ESPAÑOLA Y DE LA UNIÓN EUROPEA

\title{
LOS GRUPOS POLÍTICOS Y SU FINANCIACIÓN
}

\author{
JOSÉ FRANCISCO FERNÁNDEZ GARCÍA ${ }^{1}$ \\ Universidad de Oviedo \\ josefranciscofg@uniovi.es
}

\author{
Cómo citar/Citation \\ Fernández García, J. F. (2018). \\ Los grupos políticos y su financiación. \\ Revista de Administración Pública, 205, 291-338. \\ doi: https://doi.org/10.18042/cepc/rap.205.10
}

\section{Resumen}

El objeto de este trabajo es abordar el análisis del régimen jurídico de la financiación de los grupos políticos, particularmente, en orden a definir la naturaleza de la dotación económica que se pone a su disposición, el correcto uso o destino que cabe dar a la misma y la aplicación de los mecanismos de control, internos y externos, que implementa el sistema. Dicho estudio parte de un doble enfoque o dimensión, que permite considerar a los grupos políticos como parte integrante de las instituciones públicas en las que estos se insertan y despliegan su actividad y, a la vez, como emanación de las formaciones o partidos políticos de los que proceden sus miembros y con los que conservan un estrecho vínculo o relación jurídica durante su mandato representativo como cargos electos.

\section{Palabras clave}

Grupos políticos; financiación; control; responsabilidad contable.

1 Profesor titular de Derecho Administrativo. Director jurídico municipal del Ayuntamiento de Santander. 


\begin{abstract}
The purpose of this work is to approach the analysis of the legal regime of the funding of the political groups, particularly, in order to define the nature of the economic endowment that is available, the proper use or destination to be given to it and the application of the mechanisms of control, internal and external, that implement the system. The above mentioned study departs from a double approach or dimension, which allows to consider the political groups as an integral part of the public institutions in which they are inserted and unfold its activity and, at the same time, as emanation of the formations or political parties from which his members come and with those who retain a close link or juridical relationship during its representative mandate as elected charges.
\end{abstract}

\title{
Keywords
}

Political groups; funding; control; accounting liability. 


\section{SUMARIO}

I. INTRODUCCIÓN. II. LOS GRUPOS POLÍTICOS: 1. La noción de grupo político y su vinculación con los partidos o formaciones políticas. 2. Origen y finalidad de los grupos políticos. 3. Naturaleza. 4. La capacidad jurídica de los grupos políticos y su control por los tribunales de justicia. 5. Constitución, régimen y extinción de los grupos políticos: 5.1. La constitución de los grupos. 5.2. Funcionamiento y medios. 5.3. Extinción. 5.4. El grupo mixto y los concejales no adscritos. III. LA FINANCIACIÓN DE LOS GRUPOS POLÍTICOS: 1. Subvención o partida finalista. 2. El destino de la dotación económica. 3. Justificación y supervisión del gasto. 4. Responsabilidad por alcance y reintegro de las ayudas. IV. CONCLUSIONES.

\section{INTRODUCCIÓN}

Una de las principales manifestaciones de la participación de los partidos o formaciones políticas en la esfera pública tiene lugar a través de los denominados "grupos políticos».

Esta figura, no suficientemente estudiada por la doctrina jurídico-administrativa hasta la actualidad, constituye un elemento esencial de la representación democrática en el funcionamiento de las instituciones ${ }^{2}$, para cuyo desempeño se pone a su disposición el manejo tanto de recursos materiales y humanos como de la correspondiente dotación económica.

Concretamente, las cantidades percibidas por los grupos institucionales vinculados a los partidos políticos (grupos parlamentarios en las Cortes Generales y en las Asambleas Legislativas autonómicas y grupos políticos en las entidades locales) ascendieron, en el último ejercicio fiscalizado, a un total de 134,9 millones de euros ${ }^{3}$.

2 Como viene a señalar L. Morell Ocaña (1988), El régimen local español, t. I, Pamplona: Civitas Ediciones (pág. 190), los grupos políticos desempeñan cuatro tipos de funciones, de «mediación» con el electorado y los órganos de gobierno de la corporación; de «apoyo» a los cargos públicos, en el ejercicio de los derechos y deberes individuales; de «ocupación de órganos» en base a un criterio de proporcionalidad; y de «formación y defensa de opiniones", al ser una plataforma de ideas para su confrontación institucional.

3 Véase el Informe de Fiscalización de los estados contables de los partidos politicos y de las aportaciones percibidas por las fundaciones y asociaciones vinculadas, ejercicio 2013, 
En 1989 dicha aportación suponía el 15\% de los ingresos públicos percibidos por las formaciones políticas, tal como consta en el informe del Tribunal de Cuentas correspondiente a ese ejercicio. Veinticinco años después, esta dotación económica se ha incrementado en todas las instituciones, desde el Congreso a la mayoría de ayuntamientos, triplicando su peso en la financiación que aquellas reciben de las administraciones públicas ${ }^{4}$.

De hecho, hoy por hoy, los fondos que obtienen los grupos parlamentarios y municipales de las instituciones se han convertido de facto en la principal fuente de financiación de los partidos, lo que, unido al notable incremento de estas aportaciones y, en especial, a su naturaleza pública, hace aconsejable, promover el refuerzo de los elementales mecanismos de control aplicables hasta el momento, los cuales se antojan claramente insuficientes.

El objeto de este trabajo es abordar el análisis de la regulación existente en esta materia, con el fin de cubrir las principales lagunas que la práctica administrativa y los tribunales de justicia han venido a identificar, sin que el legislador haya acometido aún la necesaria labor integradora, capaz de dotar al sistema y a los propios grupos políticos de certidumbre y de seguridad jurídica en su funcionamiento.

\section{LOS GRUPOS POLÍTICOS}

\section{LA NOCIÓN DE GRUPO POLÍTICO Y SU VINCULACIÓN CON LOS PARTIDOS O FORMACIONES POLÍTICAS}

Tal como ha quedado apuntado, la presencia en las instituciones de los partidos políticos, particularmente en el ámbito parlamentario y en la esfera de las corporaciones locales, se articula a través de los grupos políticos ${ }^{5}$.

aprobado por el Pleno del Tribunal de Cuentas, en sesión celebrada el 23 de julio de 2015, en el ejercicio de la función fiscalizadora que sobre la actividad económicofinanciera de los partidos políticos le atribuye el art. 16.1 de la Ley Orgánica 8/2007.

4 Véase www.publico.es/politica/subvenciones-grupos-politicos-hucha-partidos.html. Según se indica en esta publicación, las entidades que financian en mayor medida a los grupos políticos son las Cortes Generales y los diecisiete Parlamentos autonómicos. «En 2016, estas instituciones presupuestaron un gasto de 82,1 millones de euros para este fin. Congreso y Senado dedicaron el 11 y el 13,1\% de su presupuesto, respectivamente, a subvencionar a los grupos parlamentarios. Las asambleas autonómicas emplearon, de media, un 19,2\%».

5 Véase C. Alonso Higuera (2015), «Los grupos políticos municipales», Cuadernos de Derecho Local, 37, págs. 125-180; E. Belda Pérez-Pedrero (2001), «Los grupos po- 
Ambas figuras aparecen así unidas mediante una estrecha relación umbilical, de modo que los grupos políticos son, en gran medida, extensión de los partidos de los que nacen las candidaturas o listas electorales. Incluso cabría afirmar que los grupos son el más claro exponente del papel esencial que la Constitución atribuye a los partidos políticos en nuestro modelo de Estado, en tanto que expresan el pluralismo político, concurren a la formación y manifestación de la voluntad popular y son elemento fundamental para la participación política ${ }^{6}$.

En cualquier caso, a pesar de esa asimilación formal, lo cierto es que los partidos y los grupos constituyen realidades diversas, cuya relación viene marcada por un cierto grado de autonomía o independencia funcional y orgánica ${ }^{7}$.

Tal es así que, según afirma el Tribunal Constitucional, aunque los grupos políticos sean una lógica emanación de los partidos y de las coaliciones y agrupaciones electorales, son estos representantes, y no las formaciones en cuyas listas son elegidos, quienes ostentan la exclusiva titularidad del cargo público y quienes, en consecuencia, integran la respectiva institución ${ }^{8}$.

líticos en los Ayuntamientos y Diputaciones», Revista de Derecho Político, 51, págs. 223-320. Acerca de la relevancia institucional de los grupos políticos, señala la Sala Primera del Tribunal Constitucional en su Sentencia 185/1993 de 31 mayo (RTC $1993 \backslash 185)$, que «del mismo modo que en el momento inicial subsiguiente a la constitución del Ayuntamiento el protagonismo de la elección corresponde esencialmente a las listas [...] a lo largo del mandato municipal el protagonismo solo puede corresponder a los Grupos Municipales en los que orgánicamente se han traducido las listas».

6 Véase el art. 6 de la Constitución española.

7 La STC 36/1990, de 1 de marzo, ya vino a subrayar «la relativa disociación conceptual y de personalidad jurídica e independencia de voluntades presente entre ambos [partido y grupo], de forma que no tienen por qué coincidir sus voluntades (como sucedería en los supuestos en que los grupos parlamentarios estén integrados por parlamentarios procedentes de distintas formaciones políticas, integrantes de coaliciones electorales y que hayan concurrido conjuntamente a las elecciones), aunque los segundos sean frecuentemente una lógica emanación de los primeros (FJ 1). Individualización de los grupos parlamentarios respecto de los partidos políticos, por otra parte, específicamente asumida tanto en los reglamentos parlamentarios como en la doctrina de este Tribunal (así, STC 64/2002, de 11 de marzo)».

8 Véase M. L. Balaguer Callejón (2001), «La relación entre los grupos parlamentarios y los partidos políticos en el ordenamiento jurídico-constitucional español», Anuario de Derecho Parlamentario, 10, págs. 39-50; I. Lasagabaster Herrarte (2014), «Partidos políticos y grupos municipales, un debate no cerrado sobre sus relaciones jurídicas», Revista Vasca de Administración Pública, 98, págs. 225-252. 
En este sentido, no debe olvidarse que el art. 67.2 de la Constitución prohíbe el mandato imperativo, lo que, al menos en el plano jurídico, dota de una amplia libertad de acción a los cargos electos durante su mandato.

Por tanto, habiendo optado el legislador por el encuadramiento en grupos de los representantes políticos que integran los plenos de las corporaciones y los Parlamentos, el derecho garantizado a cada grupo político de participar en los órganos internos de funcionamiento, no puede entenderse referido sino a los grupos constituidos por dichos miembros, pues, de lo contrario, el referido criterio de organización se vería abiertamente dañado?.

En definitiva, los concejales y los parlamentarios no están en las instituciones públicas en representación de los partidos por los que se presentaron en las listas, sino que actúan directamente como mandatarios de los electores, por lo que procede concluir que la representación en sentido jurídico político surge solo con la elección y es siempre representación del cuerpo electoral y nunca de aquellas formaciones que habiendo conformado las listas o candidaturas han concurrido con sus siglas al correspondiente proceso electoral ${ }^{10}$.

Esta afirmación, sin embargo, merece alguna matización, pues, si bien, paradójicamente, la Ley Orgánica 6/2002 no vincula expresamente a la disolución de un partido político la de los grupos parlamentarios constituidos por sus electos ${ }^{11}$, la expulsión o el abandono de la disciplina de aquella candidatura o formación política bajo la que hubiese concurrido un representante

9 Véase Tribunal Constitucional, Sala Segunda, Sentencia 30/1993 de 25 de enero de 1993 (Rec. 857/1990) y Sentencia 36/1990 de 1 Mar. 1990 (Rec. 1603/1987), «La titularidad del derecho a participar en un órgano interno de funcionamiento del Ayuntamiento corresponderá a los concejales, o en su caso a los grupos políticos que ellos constituyan a efectos de su actuación corporativa». En el mismo sentido se manifiesta el Tribunal Superior de Justicia de Andalucía, Sala de lo Contencioso-administrativo, Sección $1^{a}$, en Sentencia 905/2008 de 2 jun. 2008 (Rec. 1675/2001).

10 En el ámbito local, una manifestación de esa independencia entre el grupo y la formación política en cuya representación hubieran concurrido los electos en el proceso electoral la encontramos en el Real Decreto 2568/1986, de 28 de noviembre, dado que, conforme dispone su art. 29, «Corresponde a los grupos políticos designar, mediante escrito de su Portavoz dirigido al Presidente y en los términos previstos en cada caso en el presente Reglamento, a aquellos de sus componentes que hayan de representarlos en todos los órganos colegiados integrados por miembros de la Corporación pertenecientes a los diversos grupos».

11 Véase la Sentencia de 17 de diciembre de 2007 de la Sala Segunda del Tribunal Constitucional. VV. AA. (2013), "Consecuencias de la disolución de partido político", Consultor de los ayuntamientos y de los juzgados, Revista técnica especializada en administración local y justicia municipal, 4, págs. 343-344. 
popular vendrá a determinar, en cambio, la pérdida de la condición de miembro del grupo político que, en base a aquella, se hubiese conformado ${ }^{12}$.

Igualmente, según abordaremos más tarde, el Tribunal de Cuentas parte de ese mismo entronque institucional entre el partido y el grupo político, al menos desde la perspectiva de la eficacia del control financiero. Al respecto, sostiene que el partido político ha de concebirse como una única realidad económico-financiera, en la que se integra toda su organización territorial e institucional, incluyendo por tanto a los grupos de representación política en los distintos Parlamentos y en las corporaciones locales, a fin de que no quede excluida del alcance fiscalizador ninguna de sus actuaciones en esta materia ${ }^{13}$.

Ese mismo entronque ha permitido, incluso, plantear la extensión de la responsabilidad del grupo al partido o, también, al nuevo grupo que emane de la misma formación política en un posterior mandato electoral ${ }^{14}$; extremo este que choca con la propia naturaleza de los grupos y su temporalidad, dado que su extinción se produce al término de cada mandato legislativo.

\section{ORIGEN Y FINALIDAD DE LOS GRUPOS POLÍTICOS}

El nacimiento de los grupos políticos tiene una clara raíz parlamentaria, desde donde el modelo se extendió después al ámbito de la organización municipal ${ }^{15}$.

12 Véase la Sentencia del Tribunal Superior de Justicia de Madrid 859/2007: «Y llegados ya a la cuestión que constituye el eje central de la argumentación de los recurrentes, en cuya virtud el precepto legal mencionado sólo puede interpretarse en el sentido de que la condición de Concejal no adscrito sólo está prevista para aquellos Concejales que, por su propia voluntad, decidan no integrarse en el grupo político que constituya la formación política por la que han sido elegidos o que, posteriormente, la abandonen, pero no para los supuestos de expulsión del grupo al que se pertenece, pues, argumentan, se trata de un abandono involuntario no previsto en dicho precepto como determinante de la adquisición de la condición de Concejal no adscrito. Y esta interpretación no puede ser compartida porque, en el criterio de la Sala, no es esto lo que el precepto dice, ni en su sentido literal ni en su contexto ni en una interpretación sistemática del mismo».

13 Véase «Moción del Tribunal de Cuentas relativa a la modificación de la normativa sobre financiación y fiscalización de los Partidos Políticos», aprobada en su sesión de 30 de octubre de 2001.

14 Véase Saiz Arnáiz (1989), Los Grupos parlamentarios, Madrid: Congreso de los Diputados, págs. 346-347.

15 Véase A. Calonge Velázquez (2003), «Los grupos políticos municipales», Revista de Estudios de la Administración Local, 292-293, págs. 123-162; J. Castelao Rodríguez (2002), «Estatuto de los miembros de las entidades locales, Los grupos políticos», Revista de Estudios Locales. Cunal, 57, págs. 14-31; A. Familiar Sánchez (2008), «Los grupos políticos de las Corporaciones locales», Revista de Estudios Locales. Cunal, 108, págs. 26-37. 
Para algunos autores la aparición de organizaciones estables de parlamentarios es anterior a la de los partidos políticos, considerando, incluso, que el fraccionamiento político en el Parlamento sería una de las principales causas del nacimiento de los partidos burgueses ${ }^{16}$.

De este modo, y aunque bajo otras características, el antecedente más remoto de los grupos políticos cabe encontrarlo en el sistema parlamentario inglés del siglo xviII o en el marco de la Revolución francesa. De ahí se extenderían al derecho alemán a mitad del siglo XIX, donde surgieron las «fracciones», que eran las fuerzas decisorias en los Parlamentos. Mientras que, en España, el nacimiento de los grupos políticos cabe situarlo en la II República, concretamente, con la aprobación del Reglamento de las Cortes Constituyentes de 18 de julio de $1931^{17}$.

En nuestro ordenamiento actual, la figura de los grupos parlamentarios encuentra una primera referencia en el art. 78 de la Carta Magna, donde se hace mención a aquellos en relación al reparto de los puestos en la Diputación Permanente de cada Cámara ${ }^{18}$.

Más allá de esa mención formal, que igualmente viene a reproducirse en los Estatutos de algunas comunidades autónomas ${ }^{19}$, el grueso de la regulación de los grupos políticos se encuentra recogida en los reglamentos del Congreso y el Senado ${ }^{20}$, y de las respectivas Cámaras autonómicas ${ }^{21}$.

16 Véase A. Torres del Moral (1991), Estado de Derecho y Democracia de Partidos, Madrid: Universidad Complutense (pág. 423); K. Lenk y K. F. Neumann (1980), Teoría y sociología críticas de los partidos políticos, Traducción de I. Otto, Barcelona: Anagrama (pág. 6).

17 Véase E. Belda Pérez-Pedrero (2001: 231-235).

18 Esta previsión resulta muy similar a la ya contenida en el art. 62 de la Constitución de 1931, en donde se señalaba que: «El Congreso designará de su seno una Diputación Permanente de Cortes, compuesta, como máximum, de 21 representantes de las distintas fracciones políticas, en proporción a su fuerza numérica».

19 Véase el art. 27 del Estatuto de Autonomía de Andalucía; arts. 14 y 16 del Estatuto de Autonomía del Reino de Aragón; art. 30 del Estatuto de Autonomía del Principado de Asturias; art. 11 del Estatuto de Autonomía de Canarias; arts. 12 y 14 del Estatuto de Autonomía de Cantabria; arts. 11 y 12 del Estatuto de Autonomía de Castilla-La Mancha; art. 12 del Estatuto de Autonomía de Castilla y León; arts. 20, 29 y 30 del Estatuto de Autonomía de Extremadura; art. 32.3 del Estatuto de Autonomía de Cataluńa; art. 12.4 del Estatuto de Autonomía de Galicia; arts. 13 y 15 del Estatuto de Autonomía de Madrid y art. 29 del Estatuto de Autonomía de la Región de Murcia.

20 Véase los arts. 23 y siguientes del Reglamento del Congreso y 27 y siguientes del Reglamento del Senado.

21 Véanse los arts. 20 y siguientes del Reglamento del Parlamento de Andalucía; arts. 19 y siguientes del Reglamento de las Cortes de Aragón; arts. 12 y siguientes del Reglamento de la Junta General del Principado de Asturias; arts. 22 y siguientes 
A su vez, y como ya hemos apuntado, el modelo parlamentario de los grupos políticos ha sido incorporado a la esfera local, haciéndose referencia a ellos, tanto en la Ley 7/1985, de 2 de abril, Reguladora de las Bases del Régimen Local (en particular, en los arts. 46 y 73.3) como en el Real Decreto 2568/1986, de 28 de noviembre, por el que se aprueba el Reglamento de Organización, Funcionamiento y Régimen Jurídico de las Entidades Locales (arts. 13 a 29).

De toda esa regulación se desprende que la finalidad de los grupos políticos no es otra que la actuación corporativa de los cargos electos o representantes públicos, en el ámbito de la respectiva institución en la que se integran estos. De este modo, los grupos se configuran como un instrumento de organización del trabajo y como una regla para el desarrollo de la actividad de las respectivas cámaras legislativas u órganos plenarios a fin de garantizar la participación de sus miembros en los órganos o estructuras internas de funcionamiento ${ }^{22}$.

Desde esa misma perspectiva, y tal como señala el propio Tribunal Constitucional, los grupos pueden concebirse, a su vez, como una manifestación de la aplicación práctica del derecho constitucional a acceder en condiciones de igualdad a las funciones y cargos públicos, consagrado en el art. 23 de la Constitución española ${ }^{23}$.

del Reglamento del Parlamento de las Islas Baleares; arts. 20 y siguientes del Reglamento del Parlamento de Canarias; arts. 21 y siguientes del Reglamento del Parlamento de Cantabria; arts. 20 y siguientes del Reglamento del Parlamento de Castilla-La Mancha; arts. 20 y siguientes del Reglamento de las Cortes de Castilla y León; arts. 18 y siguientes del Reglamento del Parlamento de Cataluña; arts. 34 y siguientes del Reglamento de la Asamblea de Extremadura; arts. 22 y siguientes del Reglamento del Parlamento de Galicia; arts. 21 y siguientes del Reglamento de la Asamblea de Madrid; arts. 26 y siguientes del Reglamento del Parlamento de Navarra; arts. 27 y siguientes del Reglamento de la Asamblea Regional de Murcia; arts. 19 y siguientes del Reglamento del Parlamento Vasco; arts. 16 y siguientes del Reglamento del Parlamento de la Rioja; arts. 20 y siguientes del Reglamento de las Cortes Valencianas.

22 Véase E. García García (2011), «Grupos políticos municipales, constitución y modificaciones. Concejales no adscritos», El Consultor de los Ayuntamientos, 10, págs. 1265 y siguientes.

23 Tal como señala este precepto, «Los ciudadanos tienen el derecho a participar en los asuntos públicos, directamente o por medio de representantes, libremente elegidos en elecciones periódicas por sufragio universal». Véanse las Sentencias del Tribunal Constitucional de 21 de diciembre de 1989 y 15 de enero de 1993. 


\section{NATURALEZA}

La doctrina constitucionalista española está inspirada en los autores italianos y alemanes, que son quienes, principalmente, se han ocupado del examen de la naturaleza de los grupos políticos ${ }^{24}$.

El análisis de estos estudios permite advertir la existencia de dos grandes corrientes de opinión: la de aquellos que otorgan a los grupos una consideración «orgánica» y la de quienes les atribuyen un "carácter asociativo».

En efecto, desde el punto de vista de su integración institucional o corporativa y de su procedencia de una lista electoral, elaborada normalmente por un partido político, surge la doble posibilidad de concebir a los grupos políticos como órganos de los Parlamentos o de las formaciones políticas, o bien, incluso, como estructuras de dependencia mixta ${ }^{25}$.

En este sentido, el Tribunal Supremo ha señalado, en referencia a los municipios, que los grupos políticos son un elemento organizativo de la estructura de los órganos de gobierno, que se constituyen como cauce o medio esencial para que los representantes populares que forman las respectivas corporaciones participen en la actividad democrática de estas ${ }^{26}$.

Igualmente, en el ámbito parlamentario español se ha venido a señalar que los grupos son entes u órganos que integran la estructura interna de cada una de las Cámaras de las Cortes Generales ${ }^{27}$.

La segunda vía interpretativa permite entender que nos encontramos ante estructuras realmente autónomas, que tendrían la consideración de personas jurídicas de derecho público o, en su caso, de asociaciones privadas ${ }^{28}$.

El propio Tribunal Supremo se ha manifestado en esta dirección en su sentencia de 20 de mayo de 1988, al entender que los miembros de los grupos políticos se unen a ellos por razón de la identidad de sus posiciones ideológicas,

24 Véase M. A. Mirón Ortega (2001), «Subvenciones y contabilidad de los grupos parlamentarios», Corts, Anuario de derecho parlamentario, 10, págs. 190-193; N. Pérez Serrano Jáuregui (1989), Los Grupos Parlamentarios, Madrid: Tecnos, págs. 143 y siguientes.

25 Véase P. Biscaretti Di Rufia (1987), Derecho Constitucional, Madrid: Tecnos, págs. 354 y siguientes.

26 Véase la Sentencia del Tribunal Supremo de 8 de febrero de 1994.

27 Véase «Dictaminación sobre la posibilidad de embargar las asignaciones económicas de los diputados y las subvenciones de los grupos parlamentarios», (1984), Revista de las Cortes Generales, págs. 146-162.

28 Véase M. Razquín y A. Sáiz (1984), «Notas sobre la calificación jurídica de los Grupos Parlamentarios como asociaciones de derecho privado", en Jornadas de Derecho Parlamentario, 3, vol. II, págs. 1953 y siguientes. 
de la actuación política que llevan a cabo o de los intereses comunes que constituyen el sustrato definidor de los partidos.

Ahora bien, ninguna de estas dos posibilidades interpretativas apuntadas hasta ahora está exenta de matices o puede considerarse que opera con absoluta nitidez.

La posibilidad de entender que los grupos políticos son órganos internos de los partidos o, incluso, de las Cámaras o corporaciones locales, quiebra desde el momento en que sus actos jurídicos no son imputables ni a la formación política de la que surgen, ni tampoco a la institución en la que ejercen la representación popular, sino, únicamente, a una parte de los miembros de estas ${ }^{29}$.

A ello se une que ni los partidos, ni los Parlamentos, pueden ejercer ningún poder jurídico directo sobre los grupos. En el primer caso porque no existe ninguna obligatoriedad de obediencia de los acuerdos adoptados por las estructuras orgánicas de los partidos ${ }^{30}$. En el segundo caso, porque los grupos son el cauce para la conformación de la voluntad de las Cámaras y corporaciones (y no a la inversa), sin perjuicio de que en su funcionamiento institucional los grupos estén vinculados a las disposiciones legales y reglamentarias aprobadas por los poderes públicos en los que aquellos se insertan.

Además, los grupos políticos también realizan actividad fuera de las instituciones, tienen capacidad para dotarse de sus propias normas autoorganizativas y pueden decidir sobre el destino que han de dar a sus fondos, siempre que lo sea para fines propios de su funcionamiento ${ }^{31}$.

Respecto de su carácter asociativo, hay que tener en cuenta que la pertenencia a los grupos políticos no es meramente facultativa, sino que esta se instituye como un derecho-deber en el estatuto jurídico de los representantes electos.

Por otro lado, los grupos políticos están caracterizados por la nota de la transitoriedad o temporalidad, ya que su vida concluye al término de cada legislatura, incluso aunque algunos de sus miembros pudieran coincidir tras un nuevo proceso electoral.

En efecto, tras las correspondientes elecciones, los grupos políticos nacen ex novo, sin mantener vinculo jurídico alguno con la anterior lista electoral ${ }^{32}$,

29 Véase I. Torres Muro (1987), «Los órganos de gobierno de las cámaras legislativas, presidente, mesa y junta de portavoces, en el Derecho parlamentario español», Congreso de los Diputados, págs. 238 y siguientes.

30 Véase D. López Garrido (1995), «El Parlamento autonómico», en Estudios sobre el Estatuto de Autonomía de Castilla La Mancha., Cortes de Castilla-La Mancha, págs. 98 y siguientes.

31 Véase E. Belda Pérez-Pedrero (2001: 241-244).

32 Véase A. R. Olea Romacho (2016), «La fiscalización de las dotaciones económicas a los grupos políticos municipales», El Consultor, 2, págs. 135-138. 
lo cual, sin embargo, no permite desechar de manera absoluta que pudieran revelarse datos inequívocos que pongan en evidencia la asunción de las obligaciones del anterior grupo por el nuevo, procedente de la misma formación política $^{33}$.

Asimismo, una tercera nota definitoria de su naturaleza jurídica es que los grupos políticos están investidos de funciones públicas de cara a su intervención en la actividad corporativa de la institución de la que forman parte ${ }^{34}$.

Por último, cabe destacar que, según se desprende de los distintos pronunciamientos judiciales emitidos al respecto, los grupos políticos carecen de personalidad jurídica propia o independiente de la de las personas que los componen ${ }^{35}$; hecho que, unido a su temporalidad, va a tener una notable

33 Véase A. Saiz Arnáiz (1989: 347).

34 Son los grupos la base para la constitución de comisiones, a partir de un criterio de proporcionalidad; la fijación de los turnos de intervención en los debates; la formulación de ruegos y preguntas; la elaboración de mociones o la proposición de nuevas disposiciones normativas. En este sentido, el art. 23.1 del Real Decreto 2568/1986, de 28 de noviembre, establece que «los miembros de las Corporaciones Locales, a efectos de su actuación corporativa, se constituirán en grupo».

35 A este respecto, la Sala Especial del art. 61 LOPJ del Tribunal Supremo, señala en su Auto de 20 de mayo de 2003 (Rec. 6/2002): «Procede entrar a analizar la realidad jurídica que constituyen los Grupos parlamentarios». Pues bien, según el abogado del Estado expresaba en su demanda ejecutiva, citando en su argumento parte del Fundamento Jurídico Séptimo de la Sentencia de esta Sala de 27 Mar. 2003, partiendo del hecho incontrovertido de que el acta de diputado corresponde a cada representante político y no a los Partidos dentro de los cuales concurrieran aquéllos a los procesos electorales, por cuya causa la Sala declaró que el pronunciamiento se hacía «con plena independencia de que el estatuto singular de los miembros de dichos Partidos siga la suerte prevista para ellos en las normas jurídicas que resulten de aplicación», resulta luego que del tenor del artículo 19.3 del Reglamento del Parlamento Vasco y el 29.3 del Reglamento del Parlamento de Navarra, como también del 23.2 del Reglamento del Congreso de los Diputados, deriva una innegable vinculación entre Grupo parlamentario y Partido. Interesa además notar que si bien los Grupos Parlamentarios son una realidad jurídica diferente de los Partidos Políticos, es también revelador que tales Grupos carezcan de personalidad jurídica diferenciada. Así ha sido declarado, por ejemplo, por la Sentencia de la entonces Sala Cuarta del Tribunal Supremo de 27 Dic. 1985, en la que se dice lo siguiente, «Del estudio de los Reglamentos del Congreso de los Diputados de 13 Oct. 1977 y 24 Feb. 1982 y de los del Senado de 14 Oct. 1977 y 26 May. 1982 [...] de ninguna manera se deduce que los Grupos Parlamentarios estén dotados de una personalidad jurídica independiente de la de las personas que los componen, siendo únicamente uniones de Parlamentarios a los efectos del mejor funcionamiento de las actividades propias de las Cámaras, integrados por ideologías 
relevancia en relación a la consideración del grupo político como centro de imputación de responsabilidades.

Con base en todas estas notas, cabría concluir que los grupos políticos son uniones de hecho o agrupaciones temporales de representantes electos afines, al objeto de su actuación institucional conjunta, que operan de forma autónoma respecto de la organización del partido político por el que sus integrantes hubiesen concurrido al proceso electoral (pudiendo existir, incluso, grupos de composición mixta), así como de la propia corporación o cámara representativa en la que aquellos desarrollan su actividad y que, en todo caso, aunque no tienen personalidad propia reconocida en una norma, actúan en el tráfico jurídico como sujetos diferenciados.

\section{LA CAPACIDAD JURÍDICA DE LOS GRUPOS POLÍTICOS Y SU CONTROL POR LOS TRIBUNALES DE JUSTICIA}

Efectivamente, aun careciendo formalmente de personalidad jurídica, ya que ninguna norma se la atribuye ${ }^{36}$, lo cierto es que los grupos políticos son titulares de derechos y obligaciones ${ }^{37}$, reconociéndoles la jurisprudencia, asimismo, capacidad para ser parte y, por tanto, legitimación procesal activa ante los tribunales ordinarios.

Una muestra de esa capacidad jurídica autónoma de los grupos políticos, cabe encontrarla en el plano fiscal. Tal es así, que dichos entes pueden ser posibles titulares de obligaciones tributarias e incluirse dentro de los sujetos pasivos a los que se refiere el art. 35.4 de la Ley 58/2003, de 23 de diciembre, General Tributaria ${ }^{38}$, lo

afines, cuando exista número suficiente de personas, o componiendo un Grupo Mixto cuando no pueda ser en dicha forma...».

36 Según señala el art. 35 del Código Civil, tienen personalidad jurídica: «Las Corporaciones, asociaciones y fundaciones de interés público reconocidas por la ley», así como "Las asociaciones de interés particular, sean civiles, mercantiles o industriales, a las que la ley conceda personalidad propia, independiente de la de cada uno de los asociados».

37 Véase el Acuerdo de la Cámara de Cuentas de Madrid de 28 de marzo de 2014. Algunos autores diferencian entre la actividad que los grupos políticos desarrollan ad intra en la institución en la que se insertan, y la que desarrollan fuera, atribuyendo a aquellos, en el primer caso, personalidad jurídica al ser titulares de derechos y prerrogativas reconocidos en los reglamentos de las Cámaras. Véase J. M. Morales Arroyo (1990), Los grupos parlamentarios en las Cortes Generales, Madrid: CEC, págs. 350 y siguientes. De acuerdo con este precepto: «Tendrán la consideración de obligados tributarios, en las leyes en que así se establezca, las herencias yacentes, comunidades de bienes y demás entidades que, carentes de personalidad jurídica, constituyan una unidad económica o un patrimonio separado susceptibles de imposición». 
que también permite identificar a los grupos políticos con la figura de la «comunidad de bienes ${ }^{39}$.

En la misma línea abunda el Tribunal de Cuentas, que pese a sostener la falta de personalidad jurídica de los grupos políticos, les atribuye, en tanto que perciben recursos públicos para su funcionamiento, obligaciones de tipo contable y económico, que les hace quedar sujetos al control económicofinanciero del máximo órgano de fiscalización del Estado ${ }^{40}$.

La capacidad jurídica de los grupos políticos es reconocida, igualmente, por otros organismos públicos. Así, la Agencia Española de Protección de Datos sostiene que, aun no ostentando personalidad jurídica, los grupos políticos pueden tener la condición de responsables del tratamiento de datos, debiendo entenderse que resulta de aplicación a estos el régimen propio de los ficheros de titularidad privada ${ }^{41}$.

A su vez, el control jurisdiccional de los actos de los grupos políticos abunda en la idea de que, pese a no tener reconocida en la norma personalidad jurídica propia, su actuación sí puede tener trascendencia jurídica.

39 Véase el art. 392 del Código Civil.

40 En este sentido se manifestó la Sala de Justicia del Tribunal de Cuentas, en Auto de 16 de septiembre de 2004: «Como se desprende de la normativa aplicable a los grupos políticos municipales, en particular, el artículo 73 de la Ley 7/1985, de 2 de abril, Reguladora de las Bases de Régimen Local, así como el artículo 23 del Real Decreto 2568/1986, de 28 de noviembre, dichos grupos políticos desarrollan una función estrictamente corporativa, sin que tengan atribuida personalidad jurídica, tal como puede deducirse igualmente, de la doctrina del Tribunal Constitucional (por todas, SSTC de 6 de marzo de 1985, 3 de octubre de 1988, 25 de enero de 1983, 31 de mayo de 1993 y 9 de diciembre de 2002). Pero al mismo tiempo no puede desconocerse que a pesar de no poseer personalidad jurídica, sí les son reconocidas determinadas obligaciones en materia contable y económica por su entronque institucional con la estructura de los partidos políticos. En ese plano, su actividad puede suponer la percepción de recursos procedentes de la financiación pública y, en consecuencia, el sometimiento al control económico-financiero del Tribunal de Cuentas, en el marco de las normas sobre financiación de grupos políticos, cuyo exponente es, fundamentalmente, la Ley Orgánica 3/1987, de 2 de julio, modificada por la Ley Orgánica 1/2003, de 10 de marzo».

41 La Ley Orgánica 15/199 define en su art. 3.d) al responsable del fichero como «persona física o jurídica, de naturaleza pública o privada, u órgano administrativo, que decide sobre la finalidad, contenido y uso del tratamiento». Este concepto ha sido desarrollado por el art. 5.1.q) del Real Decreto 1720/2007, de 21 de diciembre, en donde se señala que "podrán ser también responsables del fichero o del tratamiento los entes sin personalidad jurídica que actúen en el tráfico como sujetos diferenciados». Véase al respecto el Informe Jurídico 0166/2008 del Gabinete Jurídico de la Agencia Española de Protección de Datos. 
No obstante, el reconocimiento de la legitimación procesal de los grupos no ha resultado pacífico en todo momento, pues, en un principio, el Tribunal Constitucional solo ha atribuido el derecho a la tutela judicial efectiva a las personas físicas o jurídicas, no a los grupos políticos carentes de personalidad, como son las fracciones políticas presentes en un órgano colegiado. De este modo, la minoría de uno de tales órganos no podía, en cuanto tal, invocar su infracción, ni acudir para remediarla ante la jurisdicción ordinaria y en consecuencia tampoco ante el Alto Tribunal en la vía de amparo ${ }^{42}$.

La legitimación procesal de los grupos políticos fue, sin embargo, reconocida a raíz de las sentencias del Tribunal Constitucional de 13 de diciembre de 1990 (en el caso de la cooficialidad de lenguas en el Senado) y de 22 de abril de 1991, en la que se otorga capacidad a los grupos del Parlamento de Cataluña para defender ante el Alto Tribunal las eventuales vulneraciones de derechos fundamentales de sus miembros, en relación con el ejercicio del cargo representativo.

En idéntica dirección se enmarcó, finalmente, la Sentencia del Tribunal Constitucional 251/2007, de 17 de diciembre de 2007, que parte de la base de distinguir a los grupos respecto de los partidos políticos de los que nacen, y del reconocimiento de la independencia de la voluntad de ambos, plasmado en su funcionamiento autónomo ${ }^{43}$.

42 Véase la Sentencia 32/1985, de 6 de marzo de 1985, de la Sala Segunda del Tribunal Constitucional (Rec. 573/1984): «Es cierto que la infracción de las normas constitucionales o, si existieran (lo que aquí no es el caso) legales o reglamentarias, que protegen a las minorías, puede ser corregida a través del recurso contencioso-administrativo que los Concejales que hayan votado en contra pueden interponer contra los acuerdos municipales (L 39/1981 de 28 Oct., artículo 9.), pero no ha sido ésta la vía escogida por los recurrentes, que acudieron ante la jurisdicción contencioso-administrativa acogidos a la L 62/1978 y vienen ante este Tribunal en demanda de amparo constitucional. La existencia o inexistencia de las mencionadas infracciones ha de ser apreciada por tanto como infracción de los derechos de todos y cada uno de los recurrentes, no del grupo político a que pertenecen. No significa esto, sin embargo, en modo alguno, que en dicha apreciación pueda hacerse abstracción del hecho de que los recurrentes son todos ellos como titulares de cargos electivos, representantes del Cuerpo Electoral Municipal, pero también, aunque en otro sentido, representantes de sus electores, quienes a su través ejercen el derecho de participación en los asuntos públicos que, como derecho fundamental, garantiza el artículo 23.1 CE y de que como tales representantes integran la minoría, cuyo tratamiento constitucional, ya descrito, debe ser tomado en consideración al determinar el contenido concreto que en su caso tienen los derechos que la CE les otorga».

43 Véase $B O E$ núm. 19 de 22 de enero de 2008: «Está fuera de toda duda que en el procedimiento de ejecución se ha dirimido una cuestión que afectaba directamente al 
Tal es la amplitud de la discrecionalidad, que debe reconocerse a las decisiones de los grupos políticos que el alcance del control jurisdiccional es realmente escaso, tal como ha admitido la propia jurisprudencia ${ }^{44}$.

Pese a ello, el control de la actuación de los grupos políticos es un parámetro que va a confirmar gran parte de las notas que dejamos apuntadas al abordar la cuestión de su naturaleza jurídica. En efecto, una manifestación más de que los grupos no son órganos de las instituciones en las que se insertan, es que sus actos no son objeto de control por estas, sino directamente por los tribunales de justicia.

También se pone de manifiesto que, pese a su carácter asociativo, los grupos políticos van más allá del ámbito jurídico privado, al desempeñar funciones de marcado carácter y trascendencia pública. Este extremo hace, por

Grupo Parlamentario demandante de amparo, cuál es su disolución como consecuencia de la declaración de ilegalidad en la Sentencia a ejecutar de tres partidos políticos respecto a los que se le tiene por instrumento de acción política. Es notorio que la disolución de un grupo parlamentario puede entrañar graves lesiones de los derechos de participación y representación política garantizados por el artículo $23 \mathrm{CE}$. Y no lo es menos que tales derechos confieren a su titular ex artículo 24.1 CE un indiscutible interés legítimo en el acceso a los procedimientos judiciales en los que puedan verse menoscabados. En otras palabras, sin entrar a abordar ahora, por no suscitarse en la demanda ni ser necesario para su resolución, la facultad de un órgano judicial y, en su caso, el alcance de ésta, para declarar la disolución de un grupo parlamentario, es evidente desde la perspectiva del derecho a la tutela judicial efectiva (artículo 24.1 CE) el derecho del grupo parlamentario a acceder en defensa de sus intereses legítimos al procedimiento judicial en el que se acuerde la mencionada disolución; derecho que, en consecuencia, ha de ser respetado por los órganos jurisdiccionales [...] Este Tribunal Constitucional ha asumido que partidos políticos y grupos parlamentarios son realidades conceptualmente distintas, por lo que la afirmación de su identidad fáctica en un caso concreto no puede erigirse en criterio que impida al grupo parlamentario concernido el acceso al proceso precisamente para cuestionar esa identidad, ya que de ese debate dependerá el que finalmente se decida su disolución o su continuidad. Para el Tribunal Supremo, la relación entre el partido y el grupo es de perfecta identidad, siquiera sea en el terreno de lo fáctico; para el demandante de amparo, por el contrario, dicha relación es inviable con el alcance que se le ha dado en las resoluciones judiciales impugnadas. Tales son los términos en los que viene a constituirse la cuestión de fondo planteada en el procedimiento de ejecución núm. 1-2003, siendo evidente que no puede negarse la legitimación para personarse en el mismo al grupo parlamentario que pretende discutir el criterio asumido por la Sala Especial del artículo 61 LOPJ en cuanto a su identidad con los partidos disueltos».

44 Véanse las Sentencias del Tribunal Supremo de 8 de febrero de 1994 y 14 de mayo de 2002. 
ejemplo, que, a diferencia de lo que ocurre con los partidos o formaciones políticas, la jurisdicción contencioso-administrativa ejerza una clara vis atractiva para conocer de los asuntos que afectan al control de los grupos ${ }^{45}$, pese a que no estemos, comúnmente, ante verdaderos actos administrativos ${ }^{46}$.

En este sentido, la sentencia del Tribunal Supremo de 14 de mayo de 2002 otorga a esta jurisdicción el conocimiento de la expulsión de un representante de un grupo político, realizada por el propio grupo y no por el partido del que había derivado la candidatura, dada la consideración que cabe atribuir a aquellos como pieza básica del engranaje institucional ${ }^{47}$.

45 Algunos autores entienden que ese efecto atractivo de la jurisdicción contenciosoadministrativa obedece al hecho de que la publicidad de los acuerdos y decisiones de los grupos políticos, cuando afectan a la institución, se instrumentan sobre un acta de sus órganos administrativos, tal como ocurre, por ejemplo, con la dación de cuenta al Pleno de la constitución de un grupo o de la expulsión de alguno de sus miembros. Véase E. Belda Pérez-Pedrero (2001: 283-284).

46 En base a este último extremo surgen, precisamente, las voces discrepantes. Cabe citar en este punto el voto particular emitido en la citada Sentencia del Tribunal Supremo de 8 de febrero de 1994, en el que se pone de relieve que la toma de conocimiento por el Pleno de un acuerdo de expulsión de un grupo municipal, no es un acto ni una actuación administrativos susceptibles de revisión jurisdiccional, pues «no hay vínculos administrativos en juego, no se ejercitan potestades administrativas o de índole disciplinaria o sancionadora». En términos similares se pronuncia el Tribunal Superior de Justicia de la Comunidad Valenciana, en su Auto de 11 de marzo de 1997: «estamos ante un acuerdo interno de un grupo político de un Ayuntamiento, sin naturaleza administrativa, sino civil por su ajenidad al Derecho Administrativo y a las funciones y competencias propias de una Corporación local. No se trata de una actuación pública municipal de un órgano administrativo, sino de una decisión interna de un grupo político que, si bien su constitución y funcionamiento se encuentra someramente regulado en el capítulo II del título Primero del RD 2568/1986, de 28 de noviembre, el acto impugnado no trasciende de las relevancias jurídico-privadas de un grupo político, al margen de sus competencias administrativas implícitas al funcionamiento de un Ayuntamiento».

47 Tal como seńala esta Sentencia de la Sala Tercera del Tribunal Supremo: «Tratándose como aquí se trata de un acto relativo, estrictamente, a la expulsión de un concejal del grupo político a que pertenecía, por parte del propio grupo municipal, y sin que incluso conste cuál es la causa de esa expulsión, es claro, que se dan todos los requisitos de identidad exigidos para aplicar el principio de igualdad y de unidad de doctrina, respecto a la sentencia citada de 8 Feb. 1994. Por otro lado, se ha de significar de acuerdo con las argumentaciones del recurrente y las valoraciones de la citada sentencia de 8 Feb. 1994, que dado que los concejales se han de constituir en grupos políticos, para su actuación corporativa y que los citados grupos, aparecen regulados, en 
Ahora bien, sin perjuicio de ese papel principal atribuible a la jurisdicción contencioso-administrativa, los grupos políticos pueden contraer, igualmente, obligaciones con terceras personas, lo que, a su vez, atribuye un claro ámbito en el control de su actividad a la jurisdicción civil y mercantil. Incluso su actividad puede estar sujeta también al orden social, en cuanto a los vínculos laborales que pueden quedar establecidos entre aquellos y el personal contratado que les auxilia en el desempeño de sus tareas.

\section{CONSTITUCIÓN, RÉGIMEN Y EXTINCIÓN DE LOS GRUPOS POLÍTICOS}

\subsection{La constitución de los grupos}

Como ya hemos apuntado, los grupos se conforman ex lege mediante la integración de representantes electos, de acuerdo a su afinidad ideológica o formación política de procedencia, y desde ese momento ejercen funciones públicas con carácter transitorio en el ámbito institucional en el que figuran insertas y al que, por tanto, quedan vinculados ${ }^{48}$.

Dependiendo del poder legislativo o del ámbito territorial de que se trate, nuestro ordenamiento prevé, no obstante, reglas distintas para la constitución de los grupos políticos.

Así, los reglamentos del Congreso y del Senado permiten que los grupos parlamentarios puedan quedar constituidos por diputados o senadores de diferentes formaciones políticas ${ }^{49}$, pero no que puedan constituir grupo

su organización más esencial, por el Real Decreto 2568/1986 citado, es claro, que las decisiones de tales grupos, no se puede entender que no trasciendan de las relaciones jurídico privadas, cual refiere la sentencia recurrida, pues, entre otras, la decisión de expulsión de un grupo, priva al concejal de participar en el grupo a que pertenecía, altera al grupo y tiene por tanto trascendencia para él y para los demás, al no poder intervenir el miembro expulsado, y por otro lado, al estar regulados los grupos políticos, en que se han de constituir los concejales para su actuación corporativa, en el Reglamento de Organización, Funcionamiento y Régimen Jurídico de las Entidades Locales, es claro que las decisiones de tales grupos sobre la expulsión de algunos de los concejales del grupo político, tienen una dimensión jurídico pública, suficiente para justificar su revisión ante esta jurisdicción y excluirle de la jurisdicción civil, al no tratarse de la expulsión de un miembro del partido por parte de los órganos competentes del Partido, que sí que es revisable ante la jurisdicción civil».

48 Véanse E. E. García García (2011: 1270); F. Santaolalla López (1984), Derecho parlamentario español, Madrid: Nacional (pág. 106).

49 Seńala al respecto el art. 23.1 RC, que: «Los Diputados, en número no inferior a quince, podrán constituirse en Grupo Parlamentario. Podrán también constituirse en Grupo 
parlamentario separado aquellos que pertenezcan a un mismo partido o a formaciones políticas que no se hayan enfrentado ante el electorado.

En cambio, en el ámbito local, la vinculación entre el grupo y la formación política de procedencia es mucho más directa, señalando, entre otras, la Ley Municipal de la Comunidad balear que los grupos se corresponden con los partidos políticos, las federaciones, las coaliciones o las agrupaciones, $\mathrm{cu}-$ yas listas hayan obtenido puestos en la corporación ${ }^{50}$.

Desde el punto de vista formal, las reglas de constitución de los grupos sí coinciden, en cambio, siendo lo común que se requiera la presentación de un escrito que habrá de estar firmado por todos sus componentes, manifestando su voluntad inequívoca al respecto, dentro de un determinado plazo.

De hecho, la integración de los representantes electos en un determinado grupo constituye una obligación, pues el ordenamiento jurídico ha optado claramente por la actuación colectiva de los representantes electos. Ese mandato imperativo está presente, entre otros preceptos, en el art. 73.3 de la LRBRL o el 23 del ROF, en los que se indica que a efectos de su actuación corporativa, los miembros de las entidades locales deben constituirse en grupos políticos.

Esta regla, sin embargo, presenta excepciones. Es el caso de la ley de régimen local de Cataluña, que solo impone la constitución de grupos políticos en los municipios de más de veinte mil habitantes ${ }^{51}$. De forma similar ocurre en la legislación aragonesa, en donde solo se obliga a su constitución en los municipios de más de 5.000 habitantes y en las provincias ${ }^{52}$.

Parlamentario los Diputados de una o varias formaciones políticas que, aun sin reunir dicho mínimo, hubieren obtenido un número de escańos no inferior a cinco $y$, al menos, el 15 por 100 de los votos correspondientes a las circunscripciones en que hubieren presentado candidatura o el 5 por 100 de los emitidos en el conjunto de la Nación». Véase el art. 76 de la Ley 20/2006, de 15 de diciembre, municipal y de régimen local de las Illes Balears. En sentido similar se expresa el art. 74.1 de la Ley 5/1997, de 22 de julio de Administración Local de Galicia; art. 11.2 de la Ley 7/1999, de 9 de abril, de Administración Local de Aragón; art. 122.2 de la Ley 1/2003, de 3 de marzo de Administración Local de la Rioja; art. 32.2 de la Ley 2/2003, de 11 de marzo, de Administración Local de Madrid; art. 134.2 de la Ley 8/2010 de Régimen Local de la Comunidad Valenciana; art. 27 de la Ley 7/2015, de 1 de abril, de Municipios de Canarias.

51 Según dispone el art. 50 del Decreto Legislativo 2/2003: «Para el mejor funcionamiento de los órganos de gobierno de la Corporación, el pleno puede acordar la creación de grupos municipales. Tienen que constituirse grupos municipales en los municipios de más de veinte mil habitante».

52 Véase el art. 111.1 de la Ley 7/1999, de 9 de abril, de Administración Local de Aragón. 
De lo que no cabe duda es de que la facultad de constituir un grupo político, en la forma y con los requisitos fijados en la respectiva norma, corresponde a los propios representantes electos, perteneciendo dicha facultad al núcleo de su función representativa.

Dada la configuración de los grupos políticos como entes imprescindibles y principales en la organización y funcionamiento de las instituciones, así como en el desempeńo de las funciones y los beneficios que conlleva la adquisición de tal «status», aquella facultad constituye una manifestación constitucionalmente relevante del «ius in officium».

De este modo, la decisión por la que se aceptan o deniegan las correspondientes declaraciones de voluntad de los cargos electos de constituir un determinado grupo político es una decisión con valor declarativo y no constitutivo, si bien las facultades que a la Mesa de la Cámara o al presidente de la corporación le corresponden en orden a la constitución de los grupos son de carácter reglado, debiendo limitarse a constatar si la constitución del grupo reúne los requisitos reglamentariamente establecidos y rechazarla en caso de incumplimiento de aquellos requisitos salvo que resulten subsanables ${ }^{53}$.

\subsection{Funcionamiento y medios}

Los grupos despliegan su actividad internamente, disciplinando la relación de sus miembros y, a su vez, ejercen la representación política externa de todo el colectivo en el seno de la institución pública en la que se encuentran encuadrados. Pese a ese papel protagonista, las funciones y atribuciones de los grupos no pueden comportar, en ningún caso, menoscabo de las que la legislación atribuye a los órganos municipales y a los propios miembros del Parlamento o corporación municipal ${ }^{54}$.

En el ámbito interno, el funcionamiento de los grupos políticos está basado en el principio de autoorganización ${ }^{55}$. De hecho, ya hemos indicado que los grupos se constituyen en virtud de la voluntad manifestada por los cargos electos, y es el propio colectivo (más allá de la facultad que se reserva el partido

53 Véase la Sentencia 175/2010, de 21 de enero del Tribunal Superior de Justicia de Madrid.

54 Véase el art. 112.2 de la Ley 7/1999, de 9 de abril, de Administración Local de Aragón; el art. 135.2 de la Ley 8/2010 de Régimen Local de la Comunidad Valenciana; el art. 51 del Decreto Legislativo 2/2003 de la Ley de Régimen Local de Cataluña; el art. 76.1 Ley 20/2006, de 15 de diciembre, municipal y de régimen local de las Islas Baleares. De manera explícita, el art. 27.4 de la Ley 7/2015, de 1 de abril de Municipios de Canarias, señala que «cada grupo político municipal tiene libertad de autoorganización, debiendo comunicar al alcalde la forma elegida». 
político) quien puede determinar la expulsión de alguno de sus miembros o, llegado el caso, de proceder a su disolución.

Al mismo tiempo, corresponde al grupo designar a su portavoz, configurar una estructura de gobierno y aprobar unas normas internas de funcionamiento.

En el marco de la esfera institucional, los grupos designan a sus representantes en las comisiones u órganos colegiados, hacen uso de los turnos de palabra, someten asuntos a debate, formulan mociones o preguntas y expresan su voluntad mediante el ejercicio del derecho a voto que corresponde a sus miembros.

Asimismo, a través de las juntas de portavoces se encauzan las peticiones de los grupos en relación a su funcionamiento y a su participación en la vida del Parlamento o Corporación, se consensúa el régimen de los debates corporativos en determinadas sesiones y los grupos acceden a las informaciones que la presidencia les proporciona para difundir entre sus miembros ${ }^{56}$.

Dado el relevante papel institucional que desarrollan los grupos políticos, los Parlamentos y corporaciones en los que se insertan deben dotarles de una serie de medios o instrumentos necesarios, de acuerdo a su representatividad. A este respecto, en la esfera local el art. 27 del ROF señala que, en la medida de las posibilidades de cada entidad, los grupos dispondrán de un despacho o local para reunirse de manera independiente y recibir visitas de ciudadanos, contarán con una infraestructura mínima de medios personales y materiales ${ }^{57}$ y podrán acceder a la correspondiente dotación económica para su sostenimiento.

Aunque dedicaremos la segunda parte de este estudio a analizar el sostenimiento y la financiación de los grupos políticos, cabe advertir que los gastos derivados de esta aportación de medios materiales y personales, bien pueden sufragarse directamente por la corporación o la Cámara respectiva, como si se tratase del suministro a un servicio administrativo más, o bien se puede articular a través de una dotación económica que se asigna a cada grupo, de

56 Véase el art. 113 de la Ley 7/1999, de 9 de abril, de Administración Local de Aragón; el art. 136 de la Ley 8/2010, de 23 de junio de Régimen Local de la Comunidad Valenciana; el art. 78 de la Ley 20/2006, de 15 de diciembre de la Ley de Régimen Local de las Islas Baleares.

57 Véase VV. AA. (2007), «Dotación de medios materiales en la sede de la entidad local», Consultor de los ayuntamientos y de los juzgados, Revista técnica especializada en administración local y justicia municipal, 15-16, págs. 2546-2547; VV. AA. (2013), «Derecho de los grupos municipales a la asignación de local», Consultor de los ayuntamientos y de los juzgados, Revista técnica especializada en administración local y justicia municipal, 13, págs. $1270-1271$. 
forma periódica, sometida a un régimen jurídico vagamente establecido hasta la fecha.

Para poder percibir esa dotación económica del Parlamento o la corporación, los grupos deben realizar la correspondiente declaración censal de alta fiscal, obtener un NIF diferenciado al del partido político del que emergen y abrir su propia cuenta corriente, en la que deberá ingresarse dicha aportación ${ }^{58}$.

Cumplidos esos requisitos, los grupos políticos pueden también desplegar su actividad ad extra y, por tanto, quedan habilitados para suscribir contratos, expedir facturas, compensar el IVA repercutido y, en su caso, actuar en calidad de empresarios respecto del personal auxiliar o colaborador que les preste servicio ${ }^{59}$.

\subsection{Extinción}

Existen diferentes motivos por los que un grupo político puede quedar extinguido. El más común de ellos es la finalización de la legislatura o el mandato para el que fueron elegidos sus miembros, pues como ya hemos dejado dicho, la temporalidad o transitoriedad es una de las principales notas que caracteriza a los grupos políticos.

Un segundo motivo de extinción es la reducción de sus componentes por debajo de un número mínimo, cuando así venga establecido en la ley o en el reglamento respectivo. En este sentido, el art. 27.2 del Reglamento del Senado dispone que cuando los componentes de un grupo parlamentario normalmente constituido se reduzcan durante el transcurso de la legislatura a un número inferior a seis, el grupo quedará disuelto al final del período de sesiones en que se produzca esta circunstancia.

La propia voluntad de todos sus miembros también puede determinar la disolución de un grupo político.

En estos dos últimos supuestos, mientras en el ámbito parlamentario se abre la posibilidad de que los diputados recalen en otros grupos ya formados, con carácter general, lo habitual será el pase de esos representantes electos al grupo mixto.

58 Véase VV. AA. (2010), «Forma de percibir asignaciones de los grupos», Consultor de los ayuntamientos y de los juzgados, Revista técnica especializada en administración local y justicia municipal, 22, págs. 3173-3174.

59 Véase la disposición adicional $6^{a}$ de la Ley General Tributaria y el art. 18.1 del Real Decreto 1065/2007, de 27 de julio, por el que se aprueba el Reglamento General de las actuaciones y los procedimientos de gestión e inspección tributaria y de desarrollo de las normas comunes de los procedimientos de aplicación de los tributos. 
En la esfera local, la causa de extinción del grupo determina una consecuencia dispar, ya que, si bien la reducción del número de componentes debe conducir a que dichos concejales se integren en el grupo mixto, cuando la causa sea la autodisolución del grupo, el efecto debería ser el pase de sus miembros a la situación de "concejales no adscritos», a la que a continuación nos referiremos ${ }^{60}$.

Más dudas plantea el hecho de si la disolución o desaparición de un partido supone la extinción del grupo político que derivó del mismo. Al respecto, dado que los representantes electos no están en las instituciones en representación de los partidos en cuyas listas concurrieron, sino que representan a los electores, parece razonable defender la subsistencia de estos grupos en base a la libre voluntad de sus miembros de unirse para el desarrollo de su actividad corporativa o institucional ${ }^{61}$.

\subsection{El grupo mixto y los concejales no adscritos}

Mención aparte merece la situación jurídica de aquellos cargos electos que son expulsados o, bien, que deciden no integrarse o que, posteriormente, abandonan un determinado grupo político.

En el ámbito parlamentario, quienes no se integren en los plazos que fija la norma dentro del grupo promovido por su formación política, o bien lo abandonen, pasan, automáticamente, a incorporarse al grupo mixto o pueden adscribirse a otros grupos ${ }^{62}$.

En cambio, en la esfera local, la consecuencia de la no incorporación a un grupo político o de dejar de pertenecer al mismo es el pase a la condición de concejal no adscrito, situación que va a determinar una serie de consecuencias en relación a la dotación de medios económicos de los que van a disponer estos cargos electos ${ }^{63}$.

60 Así parece deducirse del art. 73.3 LRBRL, según el cual «aquéllos... que abandonen su grupo de procedencia... tendrán la consideración de miembros no adscritos».

61 Véase A. R. Olea Romacho (2016: 137).

62 De acuerdo al art. 30 RS: «1. Los Senadores que en los plazos a que se refiere el artículo 28 no se hubieren incorporado a un Grupo parlamentario de denominación específica pasarán a integrar el Grupo Mixto, cuya participación en las actividades de la Cámara será idéntica a las de los restantes [...] 3. Los Senadores que por cualquier causa dejen de pertenecer a un Grupo parlamentario de denominación específica, quedarán automáticamente incorporados al Grupo Mixto, salvo que en el plazo de tres días se adscribieran a otros Grupos ya constituidos. El Portavoz del Grupo Mixto, o el de cualquiera de estos últimos dará cuenta de las incorporaciones que se produzcan al Presidente de la Cámara». Véase VV. AA. (2004), «Derechos políticos y económicos de los concejales no adscritos», Consultor de los ayuntamientos y de los juzgados, Revista técnica especializada en administración local y justicia municipal, 11, págs. 1886-1887. 
El propio art. 73.3 LRBRL establece una cautela en este punto al indicar que los derechos económicos de los miembros no adscritos no podrán ser superiores a los que les hubiesen correspondido de permanecer en el grupo de procedencia y se ejercerán en la forma que determine el reglamento orgánico de cada corporación ${ }^{64}$.

De hecho, el propio Tribunal Constitucional ha manifestado que la no pertenencia a un grupo político, si bien no puede comportar una situación de desventaja para esos representantes públicos en relación a sus derechos de participación política, sí resulta justificado que queden sometidos a un régimen diferenciado en aspectos como la no pertenencia a la Junta de Portavoces, el régimen de dedicación o, especialmente, la pérdida de los beneficios económicos y de la propia infraestructura asociada al grupo político ${ }^{65}$.

64 El propósito de esta medida queda claro, entre otras muchas, en la Sentencia 9/2012, de 18 de enero, del Pleno del Tribunal Constitucional (Rec. 1490/2010), en la que se seńala: "Como recuerda el Fiscal General del Estado en su escrito de alegaciones, el origen del precepto impugnado se remonta al acuerdo sobre un código de conducta política en relación con el transfuguismo en las Corporaciones locales, que se firmó por la práctica totalidad de los partidos políticos con fecha 7 de julio de 1998, y que fue renovado por nuevos acuerdos de 26 de septiembre de 2000 y 23 de mayo de 2006. La finalidad de los mismos es la de respetar la voluntad de los ciudadanos manifestada en las elecciones, en cuanto constituye la expresión esencial de un régimen democrático. Con este objetivo se disponen una serie de medidas "para frenar y reducir el condenable fenómeno de deslealtad política conocido como transfuguismo" entre las que se encuentra la creación legal de la figura de los "concejales no adscritos", que no pueden integrarse en grupo alguno».

65 Véase la Sentencia 169/2009 de 9 de julio de 2009 del Tribunal Constitucional, Sala Primera (Rec. 6680/2004): «Tampoco puede estimarse, por el mismo motivo, la queja en virtud de la cual el resto de los contenidos del Acuerdo impugnado habría situado a los ahora recurrentes en una situación de desventaja respecto de la que tienen los diputados provinciales que se encuentran adscritos a un grupo político. Por una parte, la eventual situación de desventaja derivada de las limitaciones relativas a la participación en la Junta de portavoces, al régimen de dedicación exclusiva y a la pérdida de los beneficios económicos y la infraestructura asociados al grupo político no se proyectarían, según se ha razonado, sobre el ejercicio del derecho de participación política reconocido en el artículo $23 \mathrm{CE}$. Por otra parte, el distinto trato que el artículo 73.3 LBRL y, en su aplicación, el Acuerdo impugnado otorgan a los recurrentes está justificado en la diferente situación en la que se encuentran, al no haberse incorporado al grupo político constituido por la formación electoral por la que fueron elegidos, puede someterse a un régimen jurídico parcialmente diferente a los representantes que no se integran en el grupo político constituido por la formación en la que concurrieron a las elecciones respecto de aquellos que sí lo hacen, todo ello sin perjuicio de respetar 
Cabe así concluir que, en la medida que un concejal no pertenezca a un grupo político, no puede aspirar a contar con los mismos derechos económicos que se reconocen a quienes conforman esas estructuras, por lo que, en último extremo, la percepción de estas aportaciones no puede considerarse inherente, en modo alguno, al derecho a participar en los asuntos públicos consagrado en el art. $23 \mathrm{CE}$.

Por tanto, los únicos derechos que ostentan estos concejales serán los mismos que se reconocen al resto de representantes locales individualmente considerados y, en concreto, en el ámbito económico, el derecho a percibir dietas por su asistencia a los órganos de representación ${ }^{66}$.

\section{LA FINANCIACIÓN DE LOS GRUPOS POLÍTICOS}

\section{SUBVENCIÓN O PARTIDA FINALISTA}

Ya hemos avanzado que en el marco concreto de las funciones atribuidas a los grupos y a los miembros que los integran, estos pueden recibir una aportación de los presupuestos de los Parlamentos o corporaciones al objeto de contribuir a su sostenimiento para el desempeño de sus funciones.

La legislación de régimen local no califica jurídicamente dicha aportación, refiriéndose a ella de forma genérica como «asignación» o "dotación económica ${ }^{67}$. En cambio, tanto los reglamentos del Congreso y del Senado

las facultades de representación que son propias del cargo electo, pues, como se ha indicado, el diferente trato que se otorga en este caso a los diputados no adscritos no conlleva una limitación de las facultades que constituyen el núcleo de sus funciones representativas. En definitiva, las diferencias invocadas no carecen de una justificación objetiva y razonable y son proporcionadas con los fines que se persiguen, por lo que tampoco por este motivo puede ser apreciada la lesión del principio de igualdad que aducen los demandantes de amparo».

66 Véase J. Cuerda Más (2010), «Régimen jurídico de los concejales no adscritos», CEMCI, 9 (pág. 22).

67 Véase el art. 73.3 LRBRL. El art. 28.2 de la Ley 6/1988, de 25 de agosto de Régimen Local de la Región de Murcia, dispone que «los grupos políticos, mediante acuerdo plenario que así lo disponga, podrán contar con asignaciones económicas para atender a su funcionamiento». Igualmente, el art. 32.5 de la Ley 2/2003, de 11 de marzo, de Administración Local de Madrid, establece que: «Los Ayuntamientos proporcionarán a los grupos políticos municipales [...] la asignación económica que de acuerdo con sus recursos se considere idónea, todo ello en los términos de la legislación reguladora al efecto. No obstante lo anterior, los municipios superiores a veinte mil habitantes 
como los de los Parlamentos y Asambleas Legislativas de las comunidades autónomas atribuyen a la misma el carácter de «subvención» ${ }^{68}$.

En esa misma dirección incidía la —ya derogada- Ley Orgánica 3/1987 de financiación de los partidos políticos, que al referirse a las fuentes de financiación pública de estos, incluía las subvenciones estatales a los grupos parlamentarios de las Cámaras de las Cortes Generales y las subvenciones a los grupos de las Asambleas Autonómicas ${ }^{69}$.

Ciertamente, concurren respecto de dicha dotación económica las notas características que permiten hablar de auténticas subvenciones, pues nos encontramos ante la puesta a disposición de fondos públicos, con un carácter claramente finalista y de indudable interés público, que el beneficiario recibe de forma gratuita o sin contraprestación directa ${ }^{70}$.

habilitarán una partida económica específica a estos efectos». En la doctrina, véase A. Pérez Luque (1999), "Las subvenciones a los grupos políticos en la Administración Local», Consultor de los ayuntamientos y de los juzgados, Revista técnica especializada en administración local y justicia municipal, págs. 737-749.

$\mathrm{El}$ art. $28 \mathrm{RC}$ señala que «el Congreso pondrá a disposición de los Grupos Parlamentarios, locales y medios materiales suficientes y les asignará, con cargo a su Presupuesto, una subvención [...]». En el mismo sentido se manifiesta el art. 34 del RS. En la esfera autonómica, el art. 27 de la Xunta de Galicia establece que: «O Parlamento poñerá á disposición dos grupos parlamentarios locais e medios materiais suficientes e asignaralles, con cargo ao seu orzamento, unha subvención». Véase A. González-Juliana Muñoz (2014), «Las subvenciones a los grupos políticos en las asambleas legislativas españolas», Revista Digital de Derecho Administrativo, 11, págs. 77-113.

69 La vigente Ley Orgánica 8/2007, de 4 de julio, en cambio, vuelve a calificar como «aportaciones» a los fondos que las Cámaras y corporaciones entregan, respectivamente, a los grupos parlamentarios y a los grupos de representantes en los órganos de las administraciones locales.

70 Véase G. Fernández Farreres (1983), La subvención, concepto y régimen jurídico, Madrid: Instituto de Estudios Fiscales. Al respecto, el art. 2 de la Ley 38/2003, de 17 de noviembre, General de Subvenciones: «Se entiende por subvención, a los efectos de esta ley, toda disposición dineraria realizada por cualesquiera de los sujetos contemplados en el artículo 3 de esta ley, a favor de personas públicas o privadas, y que cumpla los siguientes requisitos, a) Que la entrega se realice sin contraprestación directa de los beneficiarios; b) Que la entrega esté sujeta al cumplimiento de un determinado objetivo, la ejecución de un proyecto, la realización de una actividad, la adopción de un comportamiento singular, ya realizados o por desarrollar, o la concurrencia de una situación, debiendo el beneficiario cumplir las obligaciones materiales y formales que se hubieran establecido; c) Que el proyecto, la acción, conducta o situación financiada tenga por objeto el fomento de una actividad de utilidad pública o interés social o de promoción de una finalidad pública». 
La Ley 38/2003, General de Subvenciones, otorga esa misma condición a las ayudas públicas recibidas por los grupos políticos, aunque procede a excluirlas de su ámbito de aplicación, por gozar de un régimen especial en la regulación parlamentaria y en la legislación local ${ }^{71}$.

La Sentencia 18/2011 del Tribunal de Cuentas, sobre la que volveremos al final de este trabajo, confirma el carácter de subvención pública de esas aportaciones, dejando claro que el beneficiario de la misma es, en todo caso, el grupo y no la formación o el partido político del que emergió la candidatura presentada a las elecciones.

El Tribunal Constitucional también parte de esa misma calificación al indicar que resulta evidente que la finalidad de las diversas aportaciones establecidas en beneficio de los grupos parlamentarios no es otra que la de facilitar la participación de sus miembros en el ejercicio de las funciones institucionales de la Cámara a la que pertenecen, para lo cual, precisamente, se dota a los grupos de los recursos económicos necesarios para su adecuado desenvolvimiento en la actividad institucional ${ }^{72}$.

Estas aportaciones cuentan, normalmente, con una parte fija y otra variable, sujetas, no obstante, a distintos regímenes. Así, el reglamento de la Junta General del Principado condiciona la cuantía de la parte alícuota a la composición e importancia numérica de los grupos (art. 34.2). En Navarra se limita a la parte variable la subvención que corresponde a los diputados del grupo mixto que se incorporen al mismo a lo largo de la legislatura (art. 35.2). Otros reglamentos, como el del Parlamento de las Islas Baleares y el de las Cortes de Aragón (art. 26.3), aunque mantienen, con carácter general, el carácter fijo y variable de las subvención, excluyen de esa regla al grupo mixto, que percibe una subvención fija proporcional al número de miembros que lo componen ${ }^{73}$.

71 El art. 4 de la Ley 38/2003, en su apartado d), excluye del ámbito de aplicación de esta disposición a «las subvenciones a los grupos parlamentarios de las Cámaras de las Cortes Generales, en los términos previstos en los Reglamentos del Congreso de los Diputados y del Senado, así como las subvenciones a los grupos parlamentarios de las Asambleas autonómicas y a los grupos políticos de las Corporaciones locales, según establezca su propia normativa».

72 Véase la Sentencia del Tribunal Constitucional 141/2007 de 18 de junio (RTC 2007\141).

73 Véase M. A. Mirón Ortega (2001: 195), cit. Sentencia del Tribunal Constitucional núm. 214/1990, de 20 de diciembre (RTC 1990, 214), F. 7: «[...] la graduación de la cuantía de las subvenciones exclusivamente en atención al carácter más o menos numeroso de los Grupos constituye una exigencia de equidad, si bien cabe que la proporcionalidad del reparto de las cantidades destinadas a este objeto sufra las correcciones que se estimen precisas para garantizar el funcionamiento adecuado de los Grupos más pequeños. Lo que no cabe es pretender o sostener la tesis de que la reducción de las subvenciones 
Los distintos Parlamentos también difieren respecto del peso que dan a las partes que componen este tipo de ayudas. La Asamblea de Madrid, por ejemplo, asigna un monto alto al componente fijo, protegiendo así a las formaciones más pequeñas. Otros, como la Asamblea de Extremadura, dan más peso al componente variable, primando de este modo a los grupos políticos de mayor tamaño, que ven incrementada su dotación económica en función del número de integrantes que los componen ${ }^{74}$.

El art. 73.3 de la LRBRL prevé, igualmente, que el Pleno atribuya a los grupos políticos que se constituyan en la corporación una dotación económica que contará con un componente fijo y otro variable, defiriendo su límite a lo establecido cada año en las Leyes de Presupuestos Generales del Estado.

En la esfera local se abre, sin embargo, la posibilidad, que ya hemos dejado apuntada, de que esta dotación deje de tener, en todo o en parte, el carácter de una subvención, para configurarse como una asignación o partida finalista en los presupuestos de cada ejercicio.

En ese caso, las adquisiciones de bienes y contratación de personal con destino a los grupos deberá efectuarse con cargo a la corporación y siguiendo el régimen de los gastos y pagos municipales ${ }^{75}$.

Cabe así que en las bases de ejecución del presupuesto se establezca como ordenador de los gastos y pagos a los portavoces o a los miembros de los grupos políticos que estos designen. En estos casos, las facturas deben emitirse a nombre del ayuntamiento y llevarse una contabilidad auxiliar de la ejecución de esas partidas presupuestarias.

correspondientes al Grupo Mixto dificulte o impida gravemente el cumplimiento de las funciones representativas propias, garantizadas por el artículo 23 C.E».

74 Véase www.publico.es/politica/subvenciones-grupos-politicos-hucha-partidos.html: «En Madrid, en 2015, cada grupo recibió 490.800 euros fijos más 17.800 por cada escańo; en Extremadura, en el mismo periodo, cada agrupación recibió 9.120 euros fijos a los que sumaba 24.200 por cada diputado».

75 Véase A. Ballesteros Fernández (1999), «La financiación de los grupos políticos y el control del equipo de gobierno en las sesiones ordinarias, en la Ley 11/1999, de modificación parcial de la Ley de Régimen Local», El Consultor de los Ayuntamientos, $15 / 16$, págs. 2525 y siguientes. Tal como señala este autor: «Otra solución distinta a la constitución del grupo en comunidad de bienes pasaría por dar a la asignación económica, no el carácter de subvención, sino de partidas presupuestarias finalistas en el Presupuesto de la Corporación, regulando en las bases de ejecución del Presupuesto que será ordenador de gastos y pagos el Portavoz o miembros del Grupo que éste designe. Las facturas serían emitidas, por tanto, a nombre del Ayuntamiento y cargadas a las respectivas partidas». 
Una última opción para financiar la actividad de los grupos y de sus miembros consiste en configurar esas aportaciones como una indemnización de gastos, en cuyo caso deberá aplicarse el régimen de dietas, desplazamientos y órdenes de servicio previsto en el Real Decreto 462/2002, de 24 de mayo.

\section{EL DESTINO DE LA DOTACIÓN ECONÓMICA}

Tanto la regulación parlamentaria como la legislación local son muy parcas a la hora de regular el destino que cabe dar a las aportaciones económicas que se ponen a disposición de los diferentes grupos políticos para contribuir a su funcionamiento.

El citado art. 73.3 LRBRL establece al respecto dos prohibiciones claras: ni cabe que con esas partidas se adquieran bienes que puedan ser considerados patrimoniales, ni tampoco que esos fondos se empleen para la remuneración de personal al servicio de la corporación.

De esta última previsión normativa se desprende que sí es posible, en cambio, destinar la dotación económica para la contratación de servicios profesionales externos o, en su caso, de personal laboral que no esté incluido en la plantilla fija de la propia Administración pública, requiriéndose en ese caso que el grupo político, además de contar con un NIF (necesario para realizar toda clase de operaciones mercantiles), esté, igualmente, dado de alta como empresario $^{76}$.

En principio, estos contratos serían para «obra o servicio determinado», debiendo quedar extinguidos al término del correspondiente período legislativo, pues, contrariamente, cabría considerarlos contratos indefinidos, de entenderse que opera una suerte de «subrogación de empresas» tras la constitución de los nuevos grupos políticos ${ }^{77}$.

76 Véase el art. 11.2 del Real Decreto 84/1996, de 26 de enero, por el que se aprueba el Reglamento General sobre inscripción de empresas y afiliación, altas, bajas y variaciones de datos de trabajadores en la Seguridad Social. El Estatuto de los Trabajadores considera empresario tanto a las personas físicas o jurídicas como a las comunidades de bienes o agrupaciones sin personalidad jurídica, de ahí que los grupos políticos puedan formalizar los contratos de trabajo, respondiendo sus miembros de forma solidaria de sus consecuencias.

77 Según establece el art. 44 del Real Decreto Legislativo 2/2015, de 23 de octubre, por el que se aprueba el texto refundido de la Ley del Estatuto de los Trabajadores: «1. El cambio de titularidad de una empresa, de un centro de trabajo o de una unidad productiva autónoma no extinguirá por sí mismo la relación laboral, quedando el nuevo empresario subrogado en los derechos y obligaciones laborales y de Seguridad Social del anterior, incluyendo los compromisos de pensiones, en los términos previstos en 
Cuestión aparte es el régimen jurídico al que se encuentra sujeto este personal auxiliar que presta servicio a los grupos políticos: personal administrativo, servicio de prensa, asesoría, etc.

Normalmente se tratará de personal eventual, tal como señala, expresamente, el reglamento de la Asamblea de Extremadura, cuyo art. 39.2 dispone que previa petición a la Mesa y por acuerdo de esta, los grupos parlamentarios podrán contar con personal de naturaleza eventual conforme a criterios de proporcionalidad y con cargo al Presupuesto de la Cámara.

Aunque ese personal sea contratado por la institución, corresponde su selección al propio grupo, lo mismo que la propuesta de cese y la planificación del trabajo que aquel deba desempeñar.

Debe tenerse en cuenta, no obstante, que existe cierta doctrina judicial que sostiene la impertinencia de esta fórmula ${ }^{78}$, al menos en la esfera local, ya que en realidad nos encontramos ante un personal de libre designación o de confianza de cada grupo, y no del presidente de la institución que es, en

su normativa específica, y, en general, cuantas obligaciones en materia de protección social complementaria hubiere adquirido el cedente. 2. A los efectos de lo previsto en este artículo, se considerará que existe sucesión de empresa cuando la transmisión afecte a una entidad económica que mantenga su identidad, entendida como un conjunto de medios organizados a fin de llevar a cabo una actividad económica, esencial o accesoria. 3. Sin perjuicio de lo establecido en la legislación de Seguridad Social, el cedente y el cesionario, en las transmisiones que tengan lugar por actos inter vivos, responderán solidariamente durante tres años de las obligaciones laborales nacidas con anterioridad a la transmisión y que no hubieran sido satisfechas».

78 En esta línea cabe citar la Sentencia 897/2012 de 3 de diciembre de 2012, del Tribunal Superior de Justicia de Castilla-La Mancha, Sala de lo Contencioso-administrativo (Rec. 390/2012), en la que viene a argumentarse al F.D. Sexto, que: «Por mucho que forzáramos la interpretación de la norma hasta propiciar su mayor laxitud está claro que no cabe el nombramiento de personal eventual para grupos políticos. Tanto la normativa estatal como la autonómica citadas delimitan y determinan quienes son los órganos de gobierno, y solo ellos, añadimos nosotros, que pueden disponer de este tipo de personal. Evidentemente, y de acuerdo con esa normativa solo pueden disponer de eventuales por determinación legal los órganos de gobierno de las Administraciones Públicas dentro de las que evidentemente no caben los grupos políticos que a pesar de su peculiar caracterización sin lugar a dudas no son Administración Pública. Más concretamente, en el ámbito de las Diputaciones Provinciales solo pueden estar destinados y encomendados a los servicios de la Presidencia. Aun cuando pudiera existir una práctica extendida, favorable a que los partidos políticos en el seno de las distintas instituciones donde participan cuenten y dispongan de este tipo de funcionarios, se trata de actuaciones que carecen de respaldo legal, y por consiguiente como contrarias a derecho, deben ser anuladas». 
puridad, quien tiene la atribución normativa para su nombramiento y cese, y que, además, ejerce la jefatura superior sobre el mismo ${ }^{79}$.

Sin embargo, esa posibilidad parece abonada en el Real Decreto Legislativo 5/2015, de 30 de octubre, por el que se aprueba el texto refundido de la Ley del Estatuto Básico del Empleado Público, disponiendo al respecto su art. 87.1.i) que los funcionarios de carrera serán declarados en situación de servicios especiales cuando sean designados como personal eventual por ocupar puestos de trabajo con funciones expresamente calificadas como de confianza o asesoramiento político y no opten por permanecer en la situación de servicio activo.

Hay que advertir, por otra parte, que los propios concejales del grupo son personal al servicio de la corporación y por tanto tampoco pueden percibir cantidades con cargo a estas asignaciones. Cuestión distinta es la posibilidad de que se abonen a los miembros de los grupos indemnizaciones por razón del servicio, debidamente justificadas, pero sin que ello pueda suponer remuneraciones encubiertas.

A este respecto, la Sentencia del Tribunal Superior de Justicia del País Vasco, de 23 de mayo de 2011, confirmada en casación por el Tribunal Supremo en Sentencia de 3 de julio de 2012, deja claro que el régimen de retribuciones del art. 75 de la LRBRL no puede mezclarse ni confundirse con las asignaciones a los grupos que contempla el art. 73.3 de la LRBRL y por ello no pueden destinarse estas cantidades a retribuir en modo alguno a los concejales del grupo ${ }^{80}$.

79 Según señala A. Ballesteros Fernández (1999: 2525): «Puede el Ayuntamiento poner a disposición de los Grupos personal propio, imputando su coste a las partidas presupuestarias asignadas a los mismos. Porque no sería pago de remuneraciones por el Grupo sino imputación a la partida presupuestaria de éste de los costes del personal asignado, o bien puede el Ayuntamiento contratar personal externo pagándole con cargo a las asignaciones presupuestarias, aunque, en este caso, sería difícil de defender el carácter del contrato para obra o servicio determinado, por lo que el riesgo de que este personal se convierta en fijo de la Corporación es seguro». La primera de las posibilidades que plantea este autor queda hoy cercenada, pues el art. 73 de la LRBRL, tras su modificación por Ley 11/1999, de 21 de abril, impide que esa dotación pueda destinarse «al pago de remuneraciones de personal de cualquier tipo al servicio de la Corporación».

80 Véase A. Quirós Roldán (2000), «Grupos políticos y retribuciones de los miembros de las Corporaciones locales», en A. Castillo Blanco (coord.), Modificaciones y panorama actual del régimen local español, Granada: Centro de Estudios Municipales y de Cooperación Internacional, págs. 267-322. 
La segunda de las prohibiciones antes apuntada hace referencia a la adquisición de activos fijos, bienes, acciones, derechos y obligaciones evaluables en dinero, que, en virtud de la falta de personalidad jurídica de los grupos y de su duración temporal, daría lugar a su pertenencia, en régimen de copropiedad, por parte de sus miembros o componentes.

Más allá de estas dos concretas previsiones, lo cierto es que no existe el suficiente grado de desarrollo normativo en relación con el régimen aplicable a la asignación económica de los grupos políticos, generándose de este modo una clara inseguridad jurídica. Este hecho resulta particularmente llamativo en la esfera local, dado que la reforma llevada a cabo por la Ley 27/2013, de 27 de diciembre, de racionalización y sostenibilidad de la Administración local, orientada a fortalecer el control presupuestario del gasto público, constituyó una clara oportunidad para resolver la indeterminación del art. 73.3 LRBRL respecto del régimen jurídico al que han de quedar sujetas esta clase de subvenciones ${ }^{81}$.

Dado el carácter finalista de estas aportaciones, y pese a la falta de una norma específica que delimite qué gastos pueden financiarse con cargo a la misma, lo cierto es que nos encontramos ante una materia sujeta a límites, que precisa, como es lógico, de férreos controles, de los que habremos de ocuparnos a continuación ${ }^{82}$.

Consecuentemente, pese a poder reconocer en favor de los grupos políticos una amplia discrecionalidad en este punto, el destino de estos fondos

81 Véase A. R. Olea Romacho (2016: 147).

82 En efecto, tal como tiene señalado el Tribunal de Cuentas, aunque no existe una norma que haga una enumeración concreta de los gastos que son considerados como subvencionables, ni que venga a definir qué ha de entenderse a tales efectos por justificación contable, es evidente, no obstante, que la finalidad que estas partidas deben cumplir no admite dudas y que todo gasto de fondos públicos exige la existencia de los pertinentes controles (véase Sentencia 18/2011 de 19 diciembre, F. J. Decimocuarto). La falta de establecimiento de límites por parte del legislador estatal ha sido suplida en Euskadi bajo el impulso de la Asociación de Municipios Vascos. El Acuerdo para la gobernabilidad municipal y el libre ejercicio de su cargo por concejales y alcaldes vascos de 20 de diciembre de 2007 dispuso que tales dotaciones se entregan a los grupos políticos «en orden a facilitar su trabajo social y político», añadiendo que esas asignaciones «han de servir, exclusivamente, para financiar la actividad o promoción del grupo, y su establecimiento será a razón de una cantidad por grupo y otra por concejal». A ello se une la fijación de unas cuantías máximas y mínimas, que aportan cierta uniformidad al sistema. Véase J. Q. Maraña Sánchez (2014), «Transparencia y dotación económica de los grupos políticos municipales. ST Cuentas 18/2011, de 19 de diciembre (II parte)", El Consultor de los Ayuntamientos, 3, págs. 302 y ss. 
habrá de estar justificado en todo caso en un uso estricto, encaminado exclusivamente a atender los fines relacionados con su actuación institucional en el Parlamento o corporación respectiva, sin que, por el contrario, pueda admitirse que esa dotación económica pueda servir para financiar cualquier otro tipo de actuación política.

Este planteamiento encuentra, sin embargo, una vía de escape en virtud de lo dispuesto en la vigente Ley Orgánica de Financiación de los Partidos Políticos, cuyo art. 2, Uno, e), contempla entre los recursos económicos de los partidos políticos, procedentes de la financiación pública, a las aportaciones que en su caso estas formaciones puedan recibir de los grupos parlamentarios de las Cámaras de las Cortes Generales, de las asambleas legislativas de las comunidades autónomas, de las Juntas Generales de los territorios históricos vascos y de los grupos de representantes en los órganos de las Administraciones locales.

Al margen de que este precepto puede llegar a desvirtuar el carácter finalista de la subvención o dotación económica otorgada a los grupos políticos, una segunda consecuencia que se desprende es que ello puede dar lugar a una pérdida de control interno sobre el destino último dado a esas aportaciones por parte del propio organismo financiador ${ }^{83}$.

Esa previsión normativa, en la que, por otro lado, tampoco se especifican las cuantías, criterios de reparto o destino de dichos recursos, ha conducido

83 Recuérdese que, según dispone el art. 1 de la Ley Orgánica 8/2007, «[...] la fiscalización externa de la actividad económico-financiera de los partidos políticos corresponderá exclusivamente al Tribunal de Cuentas». Señala al respecto M. A. Mirón Ortega (2016), «La fiscalización de las dotaciones económicas a grupos políticos municipales», El Consultor de los Ayuntamientos, 2, págs. 134 y siguientes, que nos encontramos ante dos disposiciones normativas que parecen decir cosas distintas, pues mientras la Ley de Bases de régimen local configura el gasto como de naturaleza finalista, dentro del ámbito municipal, la Ley Orgánica de financiación de partidos parece romper con la naturaleza finalista de la subvención, para referir que los grupos pueden financiar a los partidos, convirtiendo la aportación del 73.3 en un recurso financiador, genérico y no finalista de los partidos a través de los grupos que conforman los ayuntamientos. Consideramos que de admitir esta postura, se impediría el control interno del destino de los fondos públicos locales, al no poder fiscalizar desde el Ayuntamiento las cuentas del partido, y podría verse alterado, de manera indirecta, el destino de esta subvención que marca el régimen normativo local. Véase, igualmente, VV. AA. (2016), «Si el grupo municipal transfiere fondos de su asignación al partido político, se estaría incumpliendo la finalidad que establece la LRBRL», Consultor de los ayuntamientos y de los juzgados, Revista técnica especializada en administración local y justicia municipal, 15-16, págs. 1756-1757. 
en ocasiones a que los fondos de los grupos y de los partidos políticos lleguen a confundirse en una gestión única llevada a cabo desde los aparatos organizativos de estas formaciones, y que, incluso, estas aportaciones económicas sean transferidas directamente a las cuentas de las que son titulares los propios partidos políticos.

Esta última práctica viene a suponer una aparente quiebra del marco normativo, pues si la dotación económica no se ingresa en una cuenta específica del grupo, el Parlamento o la corporación estarían subvencionando directamente al partido político, lo cual carece del pertinente encaje legal ${ }^{84}$.

Distinto es, por ejemplo, que el grupo retribuya con su dotación económica aquellos servicios que puedan serles prestados desde su formación o partido político. Normalmente estos servicios suelen ser de asesoramiento, coordinación o trabajos auxiliares y vienen a prestarse mediante fórmulas diversas, como el contrato o un simple convenio ${ }^{85}$.

84 Este criterio ha sido asumido por la Dirección General de Cooperación Local en su referido informe, emitido en 2007, sobre distintas cuestiones en relación a la dotación económica a los grupos políticos municipales y la Ley 8/2007, de 4 de julio, sobre financiación de los partidos políticos, «el artículo $2^{\circ}$, apartado primero, letra e) establece la posibilidad de que los grupos municipales realicen aportaciones a los partidos políticos, sin detallar su ámbito territorial de representación del partido beneficiado. No parece, sin embargo, admisible la petición de los grupos políticos de que la asignación municipal sea ingresada en la cuenta de la Coalición provincial en vez de ser transferida a su cuenta específica. En dicho supuesto habría que entender que el Ayuntamiento está subvencionando directamente a la Coalición o partido político. De acuerdo con lo dispuesto en el artículo $2^{\circ}$. Uno .E) son los Grupos quienes hacen, en su caso, las aportaciones a los partidos».

El propio Tribunal de Cuentas, en Sentencia de 4 de febrero de 2010, parece admitir estas prácticas al aceptar como justificante del servicio prestado las nóminas de las personas que eran retribuidas por el partido y prestaban servicio al grupo, entendiendo que se trataba de gastos válidos, conforme al destino o finalidad prevista en el art. 73.3 LRBRL, «aquellas cantidades abonadas a las personas contratadas para prestar servicios a los grupos municipales, ya fueran pagadas directamente por los mismos o por los partidos políticos con esa finalidad, así como las abonadas en concepto de Seguridad Social, se han tenido por justificadas siempre que así haya resultado acreditado en la litis, lo que comporta demostrar los gastos concretos a que se han destinado y que los mismos se ajusten a la finalidad para la que fue concedida la subvención». Según la información recogida en www.publico.es/politica/subvenciones-grupos-politicos-hucha-partidos.html, el PSOE, entre 2011 y 2013, cobró a su grupo en la Asamblea de Madrid el 46\% del total de la subvención que les otorgó el Parlamento autonómico en ese periodo a cambio de «apoyo técnico no permanente», según concluyó la Cámara de Cuentas de Madrid en un informe de 2015, que cifró la cantidad en 1,2 millones 
En todo caso, al no preverse una regulación general en relación con las aportaciones que los grupos pueden realizar a los partidos, corresponde de nuevo a los Parlamentos y corporaciones locales determinar a través de su potestad reguladora las cuantías, los criterios de asignación y los usos que han de darse a dichas dotaciones ${ }^{86}$.

Toda esta situación ha motivado la reacción de los distintos órganos de fiscalización de cuentas, que recuerdan la necesidad de que estas aportaciones se destinen a los fines para los que fueron concedidas ${ }^{87}$, así como a la necesidad de que los grupos y las formaciones políticas lleven contabilidades separadas, de cara a su fiscalización independiente ${ }^{88} \mathrm{y}$ de que dichos gastos queden debidamente documentados ${ }^{89}$.

de euros. Según información proporcionada a eldiario.es por Ciudadanos, en 2014 este partido le cobró a su grupo político en el Parlamento de Cataluña, 860000 euros en concepto de «asesoría», el $73 \%$ de la subvención percibida. Igualmente, el grupo parlamentario popular entregó al partido 11 de los 14 millones de euros que el Parlamento andaluz les concedió como subvención entre 2012 y 2014, el 80\% del total, en concepto de «aportación a la sede regional», como figura en la contabilidad del grupo publicada en el boletín oficial del propio Parlamento andaluz.

86 Al respecto, el art. 14.6 de la de Financiación de los Partidos Políticos prevé que para la rendición de cuentas de los grupos de las corporaciones locales, se estará a lo que dispongan sus respectivos reglamentos o normativa local específica.

87 La Sindicatura de Cuentas del Principado de Asturias, en informe del ejercicio 2013, ha venido a señalar que, «la dotación a los grupos municipales no puede tener otro destino que sufragar gastos relacionados con la actuación corporativa de dichos grupos. Actuación corporativa que se erige y sirve como elemento conformador y justificador de la existencia del propio grupo municipal». Bajo este argumento cuestiona como destino adecuado para estas dotaciones económicas la transferencia realizada a los partidos políticos en virtud del artículo 2.Uno. e).

El Pleno del Tribunal de Cuentas, mediante moción de 30 de octubre de 2001, y la Cámara de Cuentas de la Comunidad de Madrid, mediante acuerdo de 28 de marzo de 2014, después de señalar que «habiendo observado frecuentes traspasos a los partidos desde los grupos parlamentarios, se recomienda que cada subvención se destine estrictamente a la finalidad para la que ha sido concedida", concluye elevando propuesta para que se establezca una "completa separación en la contabilización y fiscalización de la financiación de la actividad ordinaria de los partidos políticos respecto de la financiación de los grupos parlamentarios y de los grupos políticos de las Corporaciones locales».

89 Tal como señala la Sentencia 18/2011 de 19 diciembre del Tribunal de Cuentas, en su FJ decimoquinto: «Por lo que se refiere a las cantidades abonadas en concepto de gastos de representación y las transferencias a los Partidos Políticos, dado que conforme al artículo 28 de la Ley 6/88 de 25 de agosto, al artículo 24 del Reglamento 
Lo que queda proscrito, en todo caso, es que estas asignaciones económicas provenientes de los Parlamentos o corporaciones locales puedan financiar a fundaciones o a cualquier otra entidad vinculada a un partido político o dependiente de este ${ }^{90}$.

\section{JUSTIFICACIÓN Y SUPERVISIÓN DEL GASTO}

Tal como venimos insistiendo, es evidente que, dado que los grupos políticos gestionan en definitiva fondos públicos, la transparencia y el rigor exigible al efecto han de ser máximos.

La propia determinación de las cuantías globales que los Parlamentos y las corporaciones locales ponen en manos de los grupos políticos constituye una primera decisión que no puede quedar, sin más, al albur de su autonomía para elaborar los presupuestos, sin que hasta el momento el legislador estatal haya puesto ningún techo o fijado límite alguno al respecto.

En este sentido se manifestó la Comisión Mixta para el Congreso y el Senado en sus relaciones con el Tribunal de Cuentas, que en resolución de 11 de junio de 2002 vino a señalar que la cuantificación presupuestaria de cualquier subvención debe ser consecuencia de la correcta evaluación de los costes originados por la actividad subvencionable ${ }^{91}$.

Del mismo modo, la exigencia de la justificación del destino dado a las subvenciones otorgadas por ambos poderes financiadores resulta obligada y es consustancial a toda ayuda pública.

$\mathrm{Al}$ respecto, el reglamento del Congreso impone a los grupos parlamentarios la obligación de llevar una contabilidad específica de las subvenciones percibidas con cargo a los presupuestos de la Cámara. Esta regla, que ha sido también recogida en el art. 73.3 LRBRL y en la mayoría de los reglamentos

Orgánico del Ayuntamiento de Totana y a los acuerdos del Pleno de la Corporación antes expuestos, las subvenciones a los grupos municipales tienen por finalidad contar con asignaciones económicas para atender su funcionamiento y éstos deben llevar una contabilidad específica y justificarlas ante el Pleno, sólo se han admitido si están soportadas con documentos que acrediten el gasto final al que se han destinado, ya que de admitirse la entrega de dichos fondos a terceros como justificantes del gasto sin ningún otro documento que acredite su destino real, quedaría vaciado de contenido el control que debe realizarse de dichos fondos».

90 Véase disposición adicional 7a de la Ley Orgánica de Financiación de Partidos Políticos. Véase J. García (2013), «Las asignaciones económicas a los grupos municipales y la reforma local», http,//www.acalsl.com/blog/2013/02/las-asignaciones-economicasa-los-grupos-municipales-y-la-reforma-local.

91 Véase $B O E$, núm. 200, de 21 de agosto de 2002. 
de los Parlamentos regionales, no figura, sin embargo, en el reglamento del Senado ${ }^{92}$.

Ahora bien, las exigencias establecidas en relación a la llevanza y control de esa contabilidad específica son excesivamente genéricas y ofrecen un desarrollo desigual en los distintos ámbitos territoriales.

La regla general es que los grupos políticos pongan dicha contabilidad a disposición de la Mesa del Parlamento o del Pleno municipal «siempre que estos órganos lo soliciten»" ${ }^{93}$. Esta vaga exigencia ha determinado en la práctica una ausencia generalizada de controles internos, a realizar desde la propia institución financiadora y sus órganos de fiscalización, que posiblemente haya podido relajar, en ciertos casos, el destino o uso que se ha dado a esas dotaciones económicas que, recordemos, se otorgan con carácter finalista ${ }^{94}$.

Únicamente los reglamentos de las Cortes valencianas, del Parlamento de Cataluña y de la Junta General del Principado de Asturias establecen un plazo imperativo en este punto. En el caso de Cataluña, los grupos deben rendir cuentas anualmente de la gestión de estos fondos ante la Mesa (art. 33.3). En la Comunidad Valenciana, la contabilidad debe ponerse a disposición de la Mesa de les Corts, siempre que sea requerida y, en todo caso, al finalizar el período de sesiones (art. 283). Por su parte, el Reglamento de la Junta General del Principado establece que la puesta a disposición de la contabilidad de los grupos debe producirse con periodicidad anual, antes de que la Mesa rinda ante el Pleno el informe sobre el cumplimiento del presupuesto (art. 34.2) ${ }^{95}$.

En la Junta de Andalucía se exige la publicidad de estas subvenciones desde el año 1993, por mera resolución de la Presidencia de esta Asamblea ${ }^{96}$. En la actualidad, esa previsión se ha incorporado al reglamento orgánico, cuyo art. 25 dispone que la Mesa ordenará su publicación en el Boletín Oficial del

92 Véase VV. AA. (2016), "Contabilidad y control de las asignaciones a los grupos políticos", Consultor de los ayuntamientos y de los juzgados, Revista técnica especializada en administración local y justicia municipal, 19, págs. 2122-2124.

93 En los reglamentos de los Parlamentos de Cataluńa y el País Vasco esa actividad de control corresponde a las Comisiones de Gobierno Interior.

94 Véase J. Q. Maraña Sánchez (2014: 302 y ss.).

95 Llama no obstante la atención el argumento que el reglamento de la Asamblea Legislativa asturiana emplea para justificar la introducción del deber de puesta a disposición de la contabilidad de los grupos políticos, pues señala en su exposición de motivos que lo que se pretende con esta medida es "ganar en transparencia», cuando el objetivo real no debe ser la simple exposición de las cuentas para su control político, sino que lo que ha de conseguirse es facilitar el ejercicio efectivo de las tareas de fiscalización o control interno de ese gasto, por parte de los órganos de Intervención.

Véase J. García (2013). 
Parlamento, con el detalle de presentación que se decida, así como en el Portal de Transparencia de la propia institución ${ }^{97}$.

En la actualidad, esta última previsión constituye una obligación para todos los Parlamentos y corporaciones locales, pues la Ley de Transparencia extiende sobre estos sujetos la obligación de publicar de forma periódica y actualizada aquella información cuyo conocimiento sea relevante para garantizar la transparencia de sus actividades relacionadas con el funcionamiento y control de la actuación pública. Más concretamente, el art. 8.1.c) de la Ley 19/2013 obliga a dar publicidad a todo acto de gestión administrativa con repercusión económica o presupuestaria y, particularmente, de las subvenciones y ayudas públicas concedidas, indicando su importe, objetivo o finalidad y beneficiarios.

La Comunidad andaluza cuenta, además, con criterios establecidos para la llevanza y presentación de la contabilidad de los grupos, requiriendo que esta incluya una cuenta de resultados y un balance ${ }^{98}$.

Evidentemente, con el fin de ofrecer un fiel reflejo del manejo de esta dotación económica se hace preciso no solo disponer de los asientos contables, sino que estos han de encontrarse respaldados documentalmente, incorporando con carácter general las facturas justificativas del gasto y los saldos o movimientos bancarios ${ }^{99}$.

97 En el Parlamento de Andalucía esa transparencia se impone tanto a los grupos políticos como a sus propios miembros, estableciendo el art. 25.4 que los grupos parlamentarios deberán también comunicar anualmente, antes del 1 de febrero del año siguiente al que la declaración afecte, «las cantidades que abonen a cada Diputado o Diputada, cualquiera que fuese su concepto, que será objeto de publicación en el Boletín Oficial del Parlamento de Andalucía. Asimismo dicha información estará disponible en el Portal de Transparencia del Parlamento de Andalucía». En sentido similar se pronuncia el art. 27.2 del Reglamento de la Xunta de Galicia, que obliga a dar idéntica publicidad a la contabilidad específica que han de llevar los grupos en relación con las ayudas que perciben de esta Asamblea Legislativa.

Véase R. Cano Silva (2011), «El control político del Parlamento de Andalucía de las contabilidades de los Grupos parlamentarios y la financiación de los Partidos políticos», Revista de estudios de la administración local y autonómica, 317, págs. 235-257. Conforme a Resolución de la Presidencia del Parlamento de 29 de junio de 1993, se dispone que el detalle de la presentación será el correspondiente al nivel cuatro del plan General de Contabilidad, y respecto de su publicación en el Boletín Oficial del Parlamento, las cuentas deben presentarse en el nivel dos del Plan General de Contabilidad.

99 Como es lógico, debe tratarse de documentos correctamente diligenciados. Así, el Tribunal de Cuentas, en Sentencia 18/2011 de 19 diciembre, FJ decimosexto, ha venido a rechazar estos justificantes, cuando el documento presentado no tenga firma, no se identifica de forma detallada al perceptor o las cantidades correspondientes, o cuando 
Dichos asientos deben registrar todas las operaciones de naturaleza económica, financiera y patrimonial llevadas a cabo por los grupos políticos, con la claridad precisa para que pueda comprobarse su rendimiento, el correcto destino del gasto y el pago efectivo de este.

No obstante, donde con mayor detalle se regula esta cuestión es en el reglamento de las Cortes de Castilla-La Mancha. Al margen de establecer diferentes tipos de subvenciones, partiendo de la clase de gasto o del carácter fijo o variable de la misma, se establecen una serie de condiciones indispensable para su percepción y distintos supuestos en los que dichas ayudas no se harán efectivas.

En esta comunidad autónoma los grupos parlamentarios quedan obligados a presentar la contabilidad específica de las subvenciones correspondientes al último ejercicio, acompańada de los documentos originales que justifiquen cada uno de los asientos contables, así como la necesidad de acreditar que se

no se aporte factura alguna que respalde el gasto: «El criterio seguido basado en la doctrina jurisprudencial antes expuesta, ha consistido en dar por justificados los gastos soportados por facturas, recibos, tickets o incluso albaranes, aun cuando presenten deficiencias de tipo formal, siempre que esté identificado el concepto, el importe, el proveedor y el destinatario (bien a través del nombre, denominación social, DNI o CIF), si bien en cuanto a los gastos en restaurantes u otros de pequeña cuantía, como gasolina, correos o desplazamientos, se han admitido las facturas, recibís y tickets de los establecimientos aun cuando no esté identificado el destinatario del servicio. No se han admitido, en cambio, los justificantes que no reúnen esos requisitos ni aquéllos que son genéricos, aunque estén en papel con membrete del grupo municipal, si no se han adjuntado las facturas, recibos o tickets correspondientes que acrediten el gasto efectivamente realizado. En ocasiones, sin embargo, el órgano fiscalizador se ha mostrado más laxo en relación a la justificación documental de las cuentas». Según recoge M. A. Mirón Ortega (2016: 83) (pág. 198), con cita en el Dictamen de 21 de enero de 1993 del Consejo de Estado y en la moción de 29 de julio de 1993 del Tribunal de Cuentas: "Como dice el Consejo de Estado 'es de esencia que todo asiento contable se encuentre documentalmente respaldado de modo suficiente y adecuado a la naturaleza del gasto y al carácter de fondos públicos que las subvenciones revisten'. Sin embargo, y dado que no se trata de acreditar una inversión o gasto específico, sino de una subvención destinada a financiar la actividad genérica de los Grupos Parlamentarios, acompañar facturas o documentos justificativos hasta el importe de la ayuda recibida podría incluso dificultar la tarea de control. En estos supuestos, dice el Tribunal de Cuentas, lo procedente sería que las cuentas, con su correspondiente desarrollo en partidas, y la Memoria viniesen acompañadas de certificaciones, bajo la responsabilidad del cuentadante, de que los justificantes se encuentran a disposición del órgano fiscalizador». 
encuentran al corriente de pago de las obligaciones con la Hacienda Pública y la Seguridad Social.

El Parlamento de Castilla-La Mancha es una de las escasas instituciones que establece consecuencias jurídicas para los grupos políticos que incumplen sus obligaciones económico-financieras. En concreto, la no aportación de la contabilidad, la presentación insuficiente de las cuentas o la falta de justificación adecuada de los asientos contables determina la obligación de reintegro y la imposibilidad de acceder a una nueva subvención.

El reglamento de esta asamblea legislativa establece, además, dos previsiones que refuerzan notablemente el sistema, ya que salen al paso de algunas carencias que ya hemos dejado recogidas más atrás.

En primer lugar, se impone a los grupos parlamentarios la obligación de requerir a los partidos de los que nacen la justificación documental del destino dado a los fondos que aquellos les hubiesen transferido.

En segundo lugar, tanto la contabilidad como la justificación documental aportada por los grupos quedan sujetas al informe de fiscalización de la Intervención del Parlamento, en el que se procede a examinar la fiabilidad de los registros y estados contables presentados, con carácter previo a su elevación a la Mesa, para la adopción de los acuerdos que pudieran proceder al respecto.

Particularmente relevante resulta esta última previsión, ya que tradicionalmente se ha entendido que la mera exigencia de la «puesta a disposición» de la contabilidad de los grupos ante la Mesa del Parlamento o ante el Pleno de las corporaciones, excluía el procedimiento normal de control del gasto público ${ }^{100}$.

Sobre esta cuestión ya se manifestó la Sindicatura de Cuentas del Principado de Asturias, señalando expresamente que las dotaciones económicas de los grupos municipales debían ser fiscalizadas por la intervención del ayuntamiento en todas y cada una de sus fases, con independencia de que el Pleno, en base a las atribuciones del art. 73.3 de la LRBRL, pueda requerir a aquellos a que presenten la contabilidad que están obligados a llevar ${ }^{101}$.

En este sentido, no debe olvidarse que, según dispone el art. 189.2 del TRLHL, los perceptores de subvenciones concedidas con cargo a los presupuestos de las entidades locales están obligados a justificar la aplicación de los fondos recibidos.

100 Véase VV. AA. (2000), «Fiscalización de las cuentas de los grupos políticos financiados con aportación municipal», Consultor de los ayuntamientos y de los juzgados, Revista técnica especializada en administración local y justicia municipal, 6, págs. 937-938.

101 Informe definitivo de fiscalización, Evaluación del control interno de los Ayuntamientos de Siero, Langreo, Mieres y Castrillón, ejercicio 2012. 
Asimismo, tal como establece el art. 214.2.d) de esa misma ley, el ejercicio de la función interventora comprende la aplicación o destino dado a las subvenciones.

Ciertamente, este régimen no admite excepciones, pues, tal como ha venido a criticarse, no tendría fundamento que el ciudadano que percibe una ayuda pública sea sometido a unas reglas de control más severas que los grupos políticos ${ }^{102}$, ni que la fiscalización de una subvención pública puede convertirse en una opción en manos de un órgano que está integrado por los propios beneficiarios de la aquella ${ }^{103}$.

En este sentido, son varios los reglamentos parlamentarios que al enmarcar la dotación económica entre los derechos de los diputados, incorporan la posibilidad de su pérdida entre las sanciones de su régimen disciplinario. Así ocurre, entre otros, con el reglamento de la Asamblea de la Comunidad de Madrid, cuyo art. 34.2 establece que, ante supuestos como la falta de asistencia reiterada e injustificada a las sesiones, el quebrantamiento del deber de secreto, o la falta de realización en plazo de la declaración sobre su patrimonio, la sanción a imponer podrá hacerse extensiva a la parte alícuota de la subvención variable respecto del grupo parlamentario al que pertenezca el diputado sancionado en el momento de los hechos ${ }^{104}$.

Por último, dada la conexión existente entre los grupos y los partidos políticos, debe recordarse que el Pleno del Tribunal de Cuentas, mediante acuerdo de 26 de septiembre de 2013, ha procedido a la aprobación del Plan de Contabilidad adaptado a las formaciones políticas, en el que se impone a los partidos presentar sus cuentas consolidadas en todos sus ámbitos, incluyendo la actividad económica desarrollada por los grupos parlamentarios y municipales ${ }^{105}$.

102 Véanse M. A. Mirón Ortega (2001: 189); VV. AA. (2015), «Las asignaciones a los grupos municipales deben someterse al control de intervención", Consultor de los ayuntamientos y de los juzgados, Revista técnica especializada en administración local y justicia municipal, 2, págs. 127-128.

103 Véase A. R. Olea Romacho (2016: 141). Cit. Sentencia del Tribunal de Cuentas 4/1995, de 10 de marzo, «La justificación de los pagos no debe quedar al libre arbitrio del que gestiona y maneja los caudales o efectos públicos».

104 Véase M. A. Presno Linera (2004), «Supresión, como recursos de los partidos políticos, de las subvenciones recibidas por los grupos parlamentarios», Debates constitucionales, 6. Así ocurre también en el Parlamento de Navarra, cuyo reglamento previamente incorpora el «deber de asistencia» como uno de los «requisitos» que habrá de establecer la Mesa a la hora de permitir la percepción de las referidas asignaciones económicas por los grupos políticos (art. 35.3).

105 Véase la resolución de 8 de octubre de 2013, de la Presidencia del Tribunal de Cuentas, por la que se publica el Acuerdo del Pleno de 26 de septiembre de 2013, de apro- 
A este respecto, se presume que, salvo prueba en contrario, dichos grupos están vinculados al partido político que presentó la candidatura electoral, con independencia del grado de autonomía implantado sobre la actividad económica de los mismos.

Tal es así que, en la memoria de actuación a presentar por la formación política habrá de recogerse la información sobre los ingresos recibidos por cualquier concepto por las agrupaciones u órganos locales de las organizaciones políticas, incluidos los grupos municipales, así como la cuantía de las operaciones y aportaciones realizadas por estos a sus respectivas formaciones.

\section{RESPONSABILIDAD POR ALCANCE Y REINTEGRO DE LAS AYUDAS}

Una de las dificultades que comporta el control a ejercer sobre la dotación económica de los grupos políticos deriva de que la contabilidad que estos han de llevar no se integra habitualmente en la cuenta general que cada ańo debe aprobar la institución que los financia.

De este modo, a las limitaciones que sufren los órganos de fiscalización interna de esos Parlamentos o corporaciones locales se une el hecho de que el Tribunal de Cuentas, que sí conoce de la cuenta general ${ }^{106}$, no se ocupa, en cambio, de un modo regular, de examinar la actividad económica que despliegan los grupos políticos.

Esta situación es realmente chocante, pues el propio Tribunal de Cuentas, en su Sentencia 18/2011, de 19 diciembre, ha venido a señalar que las cantidades que se abonan a los grupos políticos, en tanto que forman parte del

bación del Plan de Contabilidad Adaptado a las Formaciones Políticas, BOE, 252, de 21 de octubre de 2013. Debe señalarse, no obstante, que en virtud de la disposición transitoria segunda de la Ley Orgánica 3/2015, de 30 de marzo, la entrada en vigor de este plan queda demorada hasta que el Pleno del Tribunal de Cuentas proceda a su adaptación a lo dispuesto en dicha ley: «Los partidos políticos, federaciones, coaliciones y agrupaciones de electores incluidos en el ámbito de aplicación de la Ley Orgánica 8/2007, de 4 de julio, sobre financiación de los partidos políticos, no estarán vinculados a lo dispuesto en el Plan de Contabilidad Adaptado a las Formaciones Políticas aprobado por Acuerdo del Pleno del Tribunal de Cuentas 26 de septiembre de 2013 en tanto no se proceda, mediante nuevo acuerdo del Pleno, a su adaptación a la presente ley de acuerdo con lo dispuesto en la disposición final octava».

106 Conforme señala el art. 31 de la Ley 7/1988, de 5 de abril, de Funcionamiento del Tribunal de Cuentas, «El ejercicio de la función fiscalizadora del Tribunal de Cuentas se llevará a cabo mediante... b) El examen y comprobación de las Cuentas Generales y parciales de todas las entidades y organismos integrantes del sector público». 
presupuesto de la entidad, han de estar integradas en la Cuenta General del organismo financiador ${ }^{107}$.

Pese a lo indicado, la labor fiscalizadora del Tribunal de Cuentas queda circunscrita habitualmente a aquellos supuestos en los que su actuación es demandada, ocasionalmente, en virtud de una denuncia ciudadana o del ejercicio de acciones promovidos desde otros grupos políticos o por las propias autoridades corporativas ${ }^{108}$.

En cualquier caso, no debe olvidarse que cualquier saldo deudor o falta de justificación en las cuentas que han de rendir quienes tienen a su cargo el manejo de fondos públicos puede dar lugar a responsabilidad por alcance ${ }^{109}$.

Esta previsión se extiende, igualmente, sobre los perceptores o beneficiarios de ayudas con cargo a los Presupuestos Generales del Estado o procedentes de entidades integrantes del sector público, tales como subvenciones ${ }^{110}$.

Por tanto, la falta de justificación de los fondos subvencionados y, en su caso, su no reintegro, supone una negligencia grave y, consecuentemente, ello lleva a incurrir en responsabilidad contable, tal como indica, entre otras, la citada Sentencia 18/2011 del Tribunal de Cuentas ${ }^{111}$.

107 Véase FJ decimotercero.

108 Véase J. García (2013).

109 Véase el art. 72 de la Ley Funcionamiento del Tribunal de Cuentas.

${ }^{110}$ Véase el art. 34.3 de la Ley Funcionamiento del Tribunal de Cuentas. Según establece el art. 38 de esta misma ley: «El examen de las cuentas que deban rendir los perceptores o beneficiarios de ayudas consistentes en subvenciones, créditos o avales del sector público, se extenderá tanto a la comprobación de que las cantidades de que se trate se han aplicado a las finalidades para las que fueron concedidas como a sus resultados».

111 En el mismo sentido, véase igualmente la Sentencia del Tribunal de Cuentas 9/2006 de 7 abril (JUR 2007\37165), FJ vigésimo: «Resulta evidente que los perceptores de subvenciones, créditos, avales y otras ayudas procedentes del sector público están obligados a su reintegro total o parcial cuando no puedan justificar total o parcialmente la inversión de los fondos recibidos con la finalidad para la que fueron otorgados. Desde este punto de vista la interrelación existente entre el artículo 49 de la Ley de Funcionamiento del Tribunal de Cuentas, de 5 de abril de 1988, con el artículo 42.1 de la Ley Orgánica 2/1982, de 12 de mayo, hace incuestionable que deben ser declarados responsables contables directos del reintegro de los perjuicios ya referidos los demandados en su condición de integrantes de los respectivos grupos políticos municipales, por el importe correspondiente, lógicamente, a su respectiva formación política. Ninguno de estos demandados ha probado que desconociera que se hubieran obtenido las mencionadas subvenciones públicas, desconocimiento que, por otro lado, aun resultando inverosímil pondría igualmente de manifiesto su falta de diligencia. Los demandados eran los responsables de la gestión de las subvenciones percibidas $y$, en consecuencia, deben ser declarados responsables contables solidarios de la falta 
Conforme señala el alto órgano fiscalizador en este pronunciamiento, la condición de perceptores de subvenciones corresponde a los integrantes de los respectivos grupos políticos, pues con independencia de que sea el propio grupo el «beneficiario» nominal de las mismas, estas se reciben por sus integrantes, al carecer aquel de personalidad jurídica ${ }^{112}$.

Por tanto, en cuanto perceptores de fondos públicos, la responsabilidad contable directa recae sobre los miembros de los grupos políticos, que son, a la postre, quienes han de responder patrimonialmente por el eventual perjuicio que pudiera llegar a causarse a las arcas públicas.

En este sentido, cabe significar que la Ley General Tributaria, en su art. 40 , dispone que en caso de disolución de entidades sin personalidad jurídica, las obligaciones tributarias pendientes de las mismas se transmiten a los miembros de dichas entidades. Del mismo modo, el art. 11 de la Ley General de Subvenciones atribuye la condición de beneficiario, en el caso de entidades sin personalidad jurídica, a la persona que haya de realizar la actividad que fundamentó su otorgamiento.

En consecuencia, debe entenderse que todos los miembros de un grupo político se hacen responsables del destino dado a la subvención, por lo que su empleo para gastos ajenos al estricto funcionamiento del grupo, o la no rendición de cuentas cuando la Mesa del Parlamento o el Pleno lo soliciten, hace que aquellos queden obligados con carácter solidario a cubrir dicho saldo ${ }^{113}$.

El Tribunal de Cuentas recuerda en este punto la especial intensidad de la diligencia exigible a quienes gestionan fondos públicos ${ }^{114}$, y al mismo tiempo

de justificación de la debida aplicación de las subvenciones percibidas por el grupo municipal al que pertenecían a la finalidad para la que fueron concedidas. Dicha falta de justificación implica vulneración de la normativa aplicable y constituye una conducta ajena al canon de diligencia que le es exigible, siendo además causa jurídicamente relevante de unos daños ocasionados al erario público municipal que pueden calificarse de reales, efectivos, económicamente evaluables e identificables respecto a concretos caudales o efectos públicos, esto es, subsumibles en los requisitos previstos en el artículo 59.1 de la Ley de Funcionamiento del Tribunal de Cuentas, 7/1988, de 5 de abril».

112 Véase S. Bueno Mora (2004), «Los sujetos de la relación jurídica subvencional. Beneficiarios y entidades colaboradoras, régimen singular de las asignaciones a grupos políticos y de las subvenciones a las asociaciones de vecinos», Cuadernos de derecho local, 6, págs. 120-130.

113 Véase A. Ballesteros Fernández (1999: 2525).

${ }_{114}$ Al respecto, señala la Sentencia 18/2011, al FJ decimotercero: «Respecto a este requisito subjetivo para la exigencia de responsabilidad contable, esta Sala ha señalado que la culpa o negligencia consiste, a tenor del artículo 1.104 del Código Civil, en la 
advierte que el desconocimiento que pudiera invocarse por parte del grupo político, lejos de eludir la negligencia, es un elemento que refuerza su gravedad ${ }^{115}$. En todo caso, ha de tomarse en consideración que, debido al propio carácter de la subvención, el control a realizar ha de obedecer al correspondiente ejercicio anual y, como es lógico, solo puede alcanzar como responsables a los que en dicha fecha o mandato legislativo hayan formado parte del grupo político fiscalizado ${ }^{116}$.

\section{CONCLUSIONES}

En virtud de cuanto ha quedado dicho en los epígrafes anteriores, cabe establecer una serie de conclusiones, que pasamos a señalar:

1) Los grupos políticos se erigen en el máximo instrumento de participación democrática en el funcionamiento de las instituciones públicas de base representativa, en cuyo seno actúan como extensión de los partidos de los que surgen las candidaturas o listas electorales. No obstante, nos encontramos ante

omisión de aquella diligencia que exija la naturaleza de la obligación y corresponda a las circunstancias de las personas, del tiempo y del lugar; en el ámbito contable hay que partir de que la diligencia exigible al gestor de fondos públicos es especialmente intensa, ya que la omisión de la diligencia adecuada en la administración de los caudales o efectos públicos puede generar un menoscabo en los mismos, susceptible de un reproche social cualificado (Sentencia 9/03, de 23 de julio), por lo que debe exigírsele una especial diligencia en el ejercicio de sus funciones para preservar el patrimonio de la comunidad (Sentencias 16/04, de 29 de julio y 4/10, de 2 de marzo). Para determinar dicha diligencia habrá que tener en cuenta el sector del tráfico y el entorno físico y social en que se proyecta la actuación del gestor, a quien, cuando lo es de fondos públicos, se exige con especial rigor el cumplimiento de sus obligaciones (Sentencia 16/04, de 29 de julio); la negligencia grave resulta predicable de quien omite las cautelas exigibles a una persona normalmente prudente, incurriendo en un descuido inexcusable, incompatible con la formación, conocimientos, experiencia y responsabilidades encomendadas o lista de deberes atribuidos (Sentencias de 17 de diciembre de 1998 y 4/06, de 29 de marzo). La previsibilidad es, por tanto, un elemento esencial a la hora de valorar la posible conducta culposa de forma que una conducta que causa un daño no puede calificarse de culposa si el daño no era previsible en la esfera normal de los acontecimientos; dicha exigencia de prever hay que considerarla, en todo caso, en la actividad normal del hombre medio, pero siempre, como hemos visto, en relación con las circunstancias que le rodean (Sentencia 6/10, de 2 de marzo)».

115 Véase la Sentencia del Tribunal de Cuentas 14/2889, de 8 de julio.

116 Véase la Sentencia del Tribunal de Cuentas 18/2011, FJ duodécimo. 
realidades diversas y su distinción va a tener efectos relevantes en la configuración del régimen de financiación de estas estructuras, pues son los grupos y no los partidos, los perceptores de la dotación económica que los Parlamentos y corporaciones locales ponen a su disposición, con el fin de garantizar su funcionamiento.

2) Dicha diferenciación hace igualmente que los grupos políticos no puedan ser considerados órganos internos de los partidos. No obstante, tampoco cabe considerarlos como órganos de las Cámaras o corporaciones locales, ya que sus actos no son imputables a estas, realizan actividad fuera de las instituciones en las que participan y pueden dotarse de sus propias normas de carácter organizativo.

En rigor, cabe afirmar que los grupos políticos son uniones de hecho o agrupaciones de cargos representativos electos, al objeto de su actuación institucional conjunta. Uniones de carácter transitorio o temporal, ya que su vida empieza y concluye con cada legislatura o mandato electoral, a las que se atribuye o enviste de funciones públicas y que, además, carecen de personalidad jurídica propia o independiente de la de las personas que las componen.

3) La diferenciación entre los grupos y los partidos políticos obedece, en esencia, al hecho de que los concejales y los parlamentarios actúan directamente como mandatarios de los electores, por lo que la representación en sentido jurídico político surge solo con la elección y es siempre representación del cuerpo electoral y nunca de aquellas formaciones que habiendo conformado las listas o candidaturas han concurrido con sus siglas al correspondiente proceso electoral. Desde esta misma perspectiva, los partidos no pueden ejercer ningún poder jurídico directo sobre los grupos, pues no existe ninguna obligatoriedad de obediencia de los acuerdos adoptados por las estructuras orgánicas de estas formaciones.

Esta dicotomía, sin embargo, no es absoluta, ya que según evidencia el examen de los pronunciamientos judiciales, el abandono de la disciplina de aquella candidatura o partido bajo el que hubiese concurrido un representante popular vendrá a determinar, en cambio, la pérdida de la condición de miembro del grupo político que, en base al mismo, se hubiese conformado.

4) Aun careciendo formalmente de personalidad jurídica, los grupos políticos son titulares de derechos en la esfera institucional en la que actúan; tienen capacidad para ser parte y, por tanto, legitimación procesal ante los tribunales de justicia; participan en el tráfico jurídico adquiriendo bienes o servicios, suscribiendo contratos y emitiendo facturas; $y$, a su vez, pueden ser titulares de obligaciones tributarias e incluirse dentro de los sujetos pasivos a los que se refiere el art. 35.4 de la Ley 58/2003, de 23 de diciembre, General Tributaria, lo que también permite identificar, en este punto, a los grupos políticos con la figura de la «comunidad de bienes». 
5) Las dotaciones económicas que perciben los grupos políticos para su funcionamiento cuentan, en todos los casos, con las notas características que permiten definirlas como auténticas "subvenciones», pues suponen la puesta a disposición de fondos públicos, con un carácter claramente finalista y de indudable interés público, como es el correcto desarrollo de su actividad institucional, que el beneficiario recibe de forma gratuita o sin contraprestación directa.

6) En la esfera local, sin embargo, la financiación de los grupos puede llegar a articularse por medio de una partida finalista en los presupuestos del ejercicio, en cuyo caso las adquisiciones de bienes y la contratación de personal con destino a los grupos deberá efectuarse con cargo a la corporación y siguiendo el régimen de los gastos y pagos municipales, en los concretos términos que se establezcan en las pertinentes bases de ejecución.

Alternativamente, también cabe configurar esa financiación como una indemnización de gastos, debiendo aplicarse en ese caso el régimen de dietas, desplazamientos y órdenes de servicio previsto en el Real Decreto 462/2002, de 24 de mayo.

7) El análisis del régimen jurídico de la financiación de los grupos políticos arroja como resultado la constatación de un importante vacío jurídico en el propio marco regulador y, en particular, en relación a dos extremos concretos: al destino que cabe dar a estos fondos y a la configuración y puesta en funcionamiento de los mecanismos internos de control que cada una de las instituciones financiadoras deberían desplegar.

8) Pese a poder reconocer en favor de los grupos políticos una amplia discrecionalidad en este punto, el destino de estos fondos habrá de estar justificado en todo caso en un uso estricto, encaminado exclusivamente a atender los fines relacionados con su actuación institucional en el Parlamento o corporación respectiva, sin que, por el contrario, pueda admitirse que esa dotación económica pueda servir para financiar cualquier otro tipo de actuación política.

9) Desde esta perspectiva, resulta criticable que la regulación contenida en la Ley Orgánica de Financiación de los Partidos Políticos haya conducido a que los fondos de los grupos y de los partidos políticos lleguen a confundirse en una gestión única llevada a cabo desde los aparatos organizativos de estas formaciones, produciéndose, en definitiva, una pérdida de control sobre el destino último dado a esas aportaciones por parte de la institución financiadora que ha de proceder a su fiscalización.

Esta práctica genera, a su vez, una cierta quiebra del marco normativo, pues si la dotación económica no se ingresa en una cuenta específica del grupo, el Parlamento o la corporación municipal estarían subvencionando directamente al partido político, sin contar para ello con el necesario soporte jurídico. 
10) La propia determinación de las cuantías globales que los Parlamentos y las corporaciones locales ponen en manos de los grupos políticos, constituye una primera decisión que no puede quedar, sin más, al albur de su autonomía para elaborar los presupuestos, siendo igualmente cuestionable que, hasta el momento, el legislador estatal no haya puesto ningún techo o fijado límite alguno al respecto.

11) Las exigencias establecidas en relación a la llevanza y control de una contabilidad específica son excesivamente genéricas y ofrecen un desarrollo desigual en los distintos ámbitos territoriales. La regla general es que los grupos políticos pongan dicha contabilidad a disposición de la Mesa del Parlamento o del Pleno municipal «siempre que estos órganos lo soliciten», conduciendo esta previsión, en la práctica, a una ausencia generalizada de controles internos a realizar desde la propia institución en la que se insertan aquellos.

12) En cualquier caso, el control político de la financiación de los grupos no puede excluir, en modo alguno, el procedimiento normal de control del gasto público, de forma que el destino dado a las dotaciones económicas que aquellos perciben debería ser fiscalizado por los órganos de intervención o fiscalización de las Cámaras y ayuntamientos, de forma preceptiva, tal como ocurre con cualquier otra partida del presupuesto.

13) Sin perjuicio de lo señalado, la fiscalización económico-financiera de los grupos políticos debería quedar sujeta, igualmente, al control regular del Tribunal de Cuentas, de tal modo que las dotaciones económicas que se ponen a su disposición queden integrados efectivamente en la cuenta general del organismo financiador.

14) Dada la falta de personalidad jurídica de los grupos políticos, la responsabilidad contable directa recae sobre sus integrantes, que son los verdaderos gestores de los fondos públicos que aquellos perciben y quienes, a la postre, han de responder patrimonialmente por el eventual perjuicio que pudiera llegar a causarse a las arcas públicas, como consecuencia del destino indebido dado a estas partidas o de la ausencia de una justificación adecuada del gasto. 